\title{
Antiplane-inplane shear mode delamination between two second-order shear deformable composite plates
}

Mathematics and Mechanics of Solids

\author{
András Szekrényes \\ Budapest University of Technology and Economics, Department of Applied Mechanics, \\ Budapest, Hungary
}

Received I4 April 2014; accepted 23 March 2015

\begin{abstract}
The second-order laminated plate theory is utilized in this work to analyze orthotropic composite plates with asymmetric delamination. First, a displacement field satisfying the system of exact kinematic conditions is presented by developing a double-plate system in the uncracked plate portion. The basic equations of linear elasticity and Hamilton's principle are utilized to derive the system of equilibrium and governing equations. As an example, a delaminated simply supported plate is analyzed using Lévy plate formulation and the state-space model by varying the position of the delamination along the plate thickness. The displacements, strains, stresses and the J-integral are calculated by the plate theory solution and compared with those by linear finite-element calculations. The comparison of the numerical and analytical results shows that the second-order plate theory captures very well the mechanical fields. However, if the delamination is separated by only a relatively thin layer from the plate boundary surface, then the second-order plate theory approximates badly the stress resultants and so the mode-II and mode-III J-integrals and thus leads to erroneous results.
\end{abstract}

\section{Keywords}

unsymmetric delamination, J-integral, mixed-mode II/III, second-order plate, energy release rate, Lévy plate formulation

\section{Introduction}

Delamination in composite plates takes place often as the result of manufacturing defects, low-velocity impact, compressive loads and free edge effect, etc. [1-9]. The resistance against delamination or interlaminar fracture is characterized by the energy release rate (ERR) and its critical value (CERR) [10-13]. In laminated composite plates the presence of delaminations and cracks reduces the strength and stiffness (e.g. $[14,15])$ and changes the dynamic properties significantly, and therefore has a major influence on the lifetime of the structure. The delamination behavior of composite materials is characterized by different specimens for mode-I [16-23], mode-II [24-26], mixed-mode I/II [27-37], mode-III [38-48], mixed-mode I/III [49] mixed-mode II/III [42, 50-59] and mixed-mode I/II/III [60-62] tests, respectively. Many other papers investigate the problem of cracked and delaminated plates from the theoretical point of view (static, dynamic load and buckling) [63-70] using analytical and finite element (FE) methods. The strip element method (SEM) is also suitable to solve problems related to laminated plates and shells. The method discretizes the layered composite structure in layers of elements. Problems including harmonic and transient wave propagation [71-75] and general static analysis [76-78] have already been solved.

Corresponding author:

András Szekrényes, Budapest University of Technology and Economics, Department of Applied Mechanics, Múegyetem rkp. 5, Building MM, I I I I Budapest, Hungary.

Email: szeki@mm.bme.hu 
The application of the SEM to the mechanical modeling of cracks in composite [79-83] and sandwich [84] plates and shells is also well-documented in the literature.

The accurate determination of the deformation around the delamination front is essential for the precise calculation of the ERR in plates. The literature offers numerous plate theories, such as the classical laminated plate theory (CLPT) [85-87], first-order (FSDT) [85, 88, 89], second-order (SSDT) [90-92] and third-order (TSDT) [85, 88, 93-97] shear deformable plate theories, the latter offer several subtheories, as well [85]. Other advanced theories including 3D elasticity and exact solutions are also available [98-106]. Finally, the layerwise and Zig-Zag theories should be mentioned [85, 107-117]. For plates without assumed material defects the improvement in the plate solution by higher-order theories compared with CLPT and FSDT is only slight, at the same time the computational efforts increase significantly [85]. In contrast, the presence of material defects (cracks and delaminations) makes the stress and strain fields more complex around the location of the defect, which can be more accurately described by the higher-order theories [118, 119].

Delamination characterization in laminated composite plates is very important to improve the structural reliability under inservice loading. The bending of delaminated composite plates induces coupled mode-II (inplane) and mode-III (antiplane) shear fracture modes. It has been shown that the coupling between antiplane-inplane shear fracture modes is significant $[120,121]$. The application of plate theories to these problems is documented only for some basic problems including inplane load and simple loading schemes (e.g. [122, 123]) Although some efforts have been made to develop mixed analytical-numerical methods using FE models and coupling constraints between the displacements and rotations in shell elements, but these works do not generalize the applicability of plate models $[124,125]$. In some recent papers the CLPT, FSDT, SSDT and TSDT were applied for symmetric lay-up and midplane delaminated plates [118, 119, 126-129]. An important aspect of these works is that a displacement field satisfying the kinematic continuity between the top and bottom elements of a double-plate system was ensured through interface constraint equations. It was found that using the proper displacement field each theory gives acceptable result for the widthwise distribution of the $J$-integral (e.g. [130]). Later, the interface constraint equations were formulated for asymmetrically delaminated plates too involving five conditions against the displacement field. The system of exact kinematic conditions (SEKC) [131] includes the continuity of the inplane and transverse displacements at the interface, moreover utilizes an optional global plane to define the reference plane of the plate. Recently it was shown that for third-order Reddy plates even the continuity of the shear strain along the interface is important [132] and therefore the revised form of the SEKC was presented. Using the SEKC it was elaborated that the FSDT theory gives acceptable result only if the delamination is close to the midplane of the plate [131]. The reason for that is FSDT provides a piecewise constant prediction for the interlaminar shear stresses, which is insufficient when the delamination divides the plate into a relatively thick and a relatively thin layer. In other words, the FSDT gives erroneous results for asymmetrically delaminated plates because it does not satisfy the traction-free boundary conditions (BCs) at the top and bottom plate surfaces. In the literature only few papers are available for the application of SSDT (e.g. [90, 91, 133, 134]), therefore in this paper that theory is applied to orthotropic plates with asymmetric delamination. Although this theory is still not able to satisfy the dynamic BCs for plate bending problems and the continuity condition of shear strains at the interface, a more accurate mechanical solution is expected compared to the FSDT [131]. The shear stresses are approximated by linear functions over the thickness of the plate, therefore a better prediction of the $J$-integral can be achieved. The governing equations of SSDT are derived using the SEKC and a system of partial differential equations (PDEs) is obtained. A simply supported plate is considered as an example and the solution was calculated by Lévy plate formulation and the state-space approach. The comparison of the analytical results to those by linear FE calculations and previous FSDT results [131] shows that SSDT captures excellently the mechanical problem, however it fails to give correct result for the ERRs when the delamination is very close to the free surface of the plate.

\section{The SEKC}

Assuming a laminated plate with a stacking sequence including orthotropic plies and an interlaminar delamination the displacement field of the uncracked portion of the plate can be captured by different plate theories. This section is essentially about the undelaminated portion of the plate. The delamination 
(a)

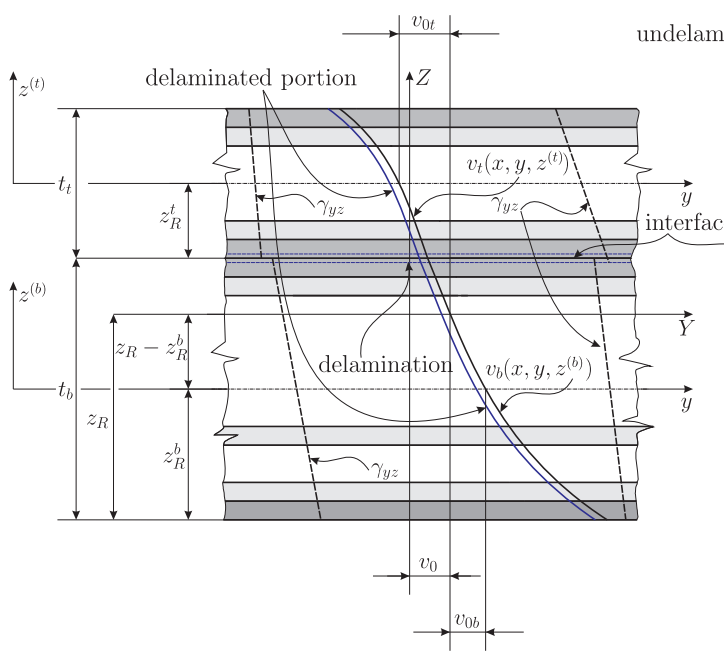

(b)

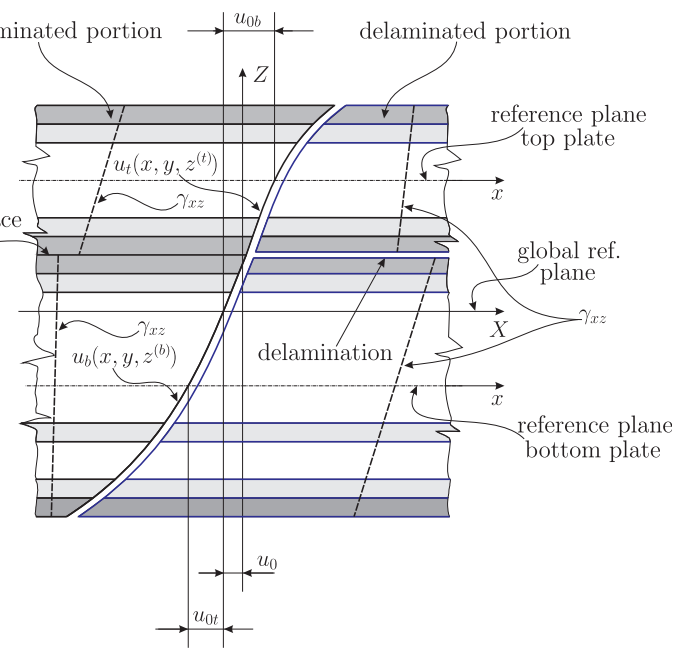

Figure I. Deformations of the top and bottom plate elements of an unsymmetrically delaminated plate in the (a) $X-Z$ and (b) $Y-Z$ planes under external load.

divides the plate into a top and bottom element, each is modeled as an equivalent single layer (ESL). Independently of the fact that whether the classical (Kirchhoff or CLPT) theory [85], FSDT [85, 86], SSDT [90], [129] or TSDT [85] is applied, the displacement field of the undelaminated part has to satisfy certain kinematic conditions. In the general case we assume that the delamination is arbitrarily placed between any two adjacent layers of the plate as is shown by Figure 1. The through thickness curves represent the second-order distributions of the inplane displacement functions. The piecewise dashed lines mean the distribution of the transverse shear strains $\left(\gamma_{x z}\right.$ and $\left.\gamma_{y z}\right)$ across the top and bottom plates. First, displacement continuity between the top and bottom layers has to be ensured in the plane of the delamination (or interface), the requirements are

$$
\left.\left(u_{t}, v_{t}, w_{t}\right)\right|_{z^{(t)}=-z_{R}^{t}}=\left.\left(u_{b}, v_{b}, w_{b}\right)\right|_{z^{(b)}=t_{b}-z_{R}^{b}}
$$

where, referring to Figure 1, $u, v$ and $w$ are the components of the displacement vector, $z^{(t)}$ and $z^{(b)}$ are the local through-thickness coordinates, $t_{b}$ and $t_{t}$ are the thicknesses of the bottom and top plates, moreover $z_{R}^{b}$ and $z_{R}^{t}$ are the positions of the reference planes of the top and bottom plates, respectively. Second, the reference plane of the uncracked plate portion should be defined according to Figure 1. The uncracked plate portion is formed by assuming a perfect bond between the top and bottom plates. At the global reference plane $(Z=0)$ the inplane displacements are equal to $u_{0}$ and $v_{0}$. If the lay-up of the laminate is unsymmetric or the delamination does not lie in the global midplane then the bendingstretching coupling [86] leads to global membrane displacements, these are denoted by $u_{0}$ and $v_{0}$. Since there is a perfect bond between the top and bottom plates of the undelaminated portion, these are the same for the top and bottom plates. Figure 1 shows that $u_{0}$ and $v_{0}$ are measured from the global $Z$ axis. The kinematic conditions are formulated for two different cases depending on the thicknesses of the top and bottom plates, respectively:

$$
z_{R} \begin{cases}\leq t_{b}: & \left.u_{b}\right|_{z^{(b)}=z_{R}-z_{R}^{b}}-u_{0}=0,\left.v_{b}\right|_{z^{(b)}=z_{R}-z_{R}^{b}-v_{0}=0} \\ \geq t_{b}: & \left.u_{t}\right|_{z^{(t)}=-\left(z_{R}^{t}-z_{R}+t_{b}\right)}-u_{0}=0,\left.v_{t}\right|_{z^{(t)}=-\left(z_{R}^{t}-z_{R}+t_{b}\right)}-v_{0}=0\end{cases}
$$

where $z_{R}$ is the position of the reference plane in the uncracked portion. It should be kept in mind, that for a single problem only two of the four above hold. Equations (1) and (2) are the SEKC in the mechanical modeling of delaminated plates. As it is shown, there are five conditions formulated. In most of the cases, for the sake of simplicity it is convenient to choose the midplane of the plate to be the reference plane $[85$, p. 113]. In this case (1)-(2) reduce to 


$$
\begin{gathered}
\left.\left(u_{t}, v_{t}, w_{t}\right)\right|_{z^{(t)}=-\frac{t_{t}}{2}}=\left.\left(u_{b}, v_{b}, w_{b}\right)\right|_{z^{(b)}=\frac{t_{b}}{2}} \\
\frac{t_{t}+t_{b}}{2}\left\{\begin{array}{cl}
\leq t_{b}: & \left.u_{b}\right|_{z^{(b)}=\frac{t_{t}}{2}}-u_{0}=0,\left.v_{b}\right|_{z^{(b)}=\frac{t_{t}}{2}}-v_{0}=0 \\
\geq t_{b}: & u_{t_{z^{(t)}}=-\frac{t_{b}}{2}}-u_{0}=0,\left.v_{t}\right|_{z^{(t)}=-\frac{t_{b}}{2}}-v_{0}=0
\end{array}\right.
\end{gathered}
$$

For plates with symmetric lay-up and midplane delamination it is required to analyze only the top (or bottom) plate (symmetric problem) [129], therefore the five conditions reduce to three only:

$$
\left.\left(u_{t}, v_{t}, w_{t}\right)\right|_{z^{(t)}=-\frac{t}{2}}=(0,0,0)
$$

As has already been mentioned, the SEKC is suitable to be implemented into any plate theory, this work presents the application by using the SSDT.

\section{Application to second-order delaminated orthotropic plates}

In this section we develop the displacement field and the governing equations for the undelaminated plate portion only. The delaminated part of the system can be captured by the standard SSDT, which is available in the literature [91]. The inplane components of the assumed displacement field in secondorder plates can be written as

$$
\begin{aligned}
& u_{\delta}(x, y, z)=u_{0}(x, y)+u_{0 \delta}(x, y)+\theta_{x \delta}(x, y) \cdot z^{(\delta)}+\phi_{x \delta}(x, y) \cdot\left[z^{(\delta)}\right]^{2} \\
& v_{\delta}(x, y, z)=v_{0}(x, y)+v_{0 \delta}(x, y)+\theta_{y \delta}(x, y) \cdot z^{(\delta)}+\phi_{y \delta}(x, y) \cdot\left[z^{(\delta)}\right]^{2}
\end{aligned}
$$

where $\delta$ takes $t$ for the top and $b$ for the bottom plate, respectively (refer to Figure 1), furthermore $u_{0}$ and $v_{0}$ are the (through-thickness) constant parts (bending-stretching coupling) of the displacement functions, $u_{0 \delta}$ and $v_{0 \delta}$ are the local constant parts (measured from the global membrane displacements, refer to Figure 1), $\theta_{x \delta}$ and $\theta_{y \delta}$ are the rotations about the $x$ and $y$ axes, $\phi_{x \delta}$ and $\phi_{y \delta}$ are the parameters of the second-order terms, respectively. Utilizing (3)-(4) and the first case in (4), moreover taking the midplanes of the top and bottom plates to be the reference planes it is possible to establish the relationship between $u_{0 \delta}, v_{0 \delta}$, the rotations and the second-order terms, respectively in the following way:

$$
\begin{aligned}
& u_{0 t}=\frac{\theta_{x t} t_{t}+\theta_{x b}\left(t_{b}-t_{t}\right)}{2}-\frac{\phi_{x t} t_{t}^{2}-\phi_{x b}\left(t_{b}^{2}-t_{t}^{2}\right)}{4}, u_{0 b}=-\frac{\theta_{x b} t_{t}}{2}-\frac{\phi_{x b} t_{t}^{2}}{4} \\
& v_{0 t}=\frac{\theta_{y t} t_{t}+\theta_{y b}\left(t_{b}-t_{t}\right)}{2}-\frac{\phi_{y t} t_{t}^{2}-\phi_{y b}\left(t_{b}^{2}-t_{t}^{2}\right)}{4}, v_{0 b}=-\frac{\theta_{y b} t_{t}}{2}-\frac{\phi_{y b} t_{t}^{2}}{4}
\end{aligned}
$$

Taking (7)-(8) back into (6) the displacement field components satisfying the SEKC requirements can be written as

$$
\begin{gathered}
u_{t}(x, y, z)=u_{0}(x, y)+\frac{\theta_{x t} t_{t}+\theta_{x b}\left(t_{b}-t_{t}\right)}{2}-\frac{\phi_{x t} t_{t}^{2}-\phi_{x b}\left(t_{b}^{2}-t_{t}^{2}\right)}{4}+\theta_{x t}(x, y) \cdot z^{(t)}+\phi_{x t}\left[z^{(t)}\right]^{2} \\
v_{t}(x, y, z)=v_{0}(x, y)+\frac{\theta_{y y} t_{t}+\theta_{y b}\left(t_{b}-t_{t}\right)}{2}-\frac{\phi_{y t} t_{t}^{2}-\phi_{y b}\left(t_{b}^{2}-t_{t}^{2}\right)}{4}+\theta_{y t}(x, y) \cdot z^{(t)}+\phi_{y t}\left[z^{(t)}\right]^{2} \\
u_{b}(x, y, z)=u_{0}(x, y)-\frac{\theta_{x b} t_{t}}{2}-\frac{\phi_{x b} t_{t}^{2}}{4}+\theta_{x b}(x, y) \cdot z^{(b)}+\phi_{x b}\left[z^{(b)}\right]^{2} \\
v_{b}(x, y, z)=v_{0}(x, y)-\frac{\theta_{y b} t_{t}}{2}-\frac{\phi_{y b} t_{t}^{2}}{4}+\theta_{y b}(x, y) \cdot z^{(b)}+\phi_{y b}\left[z^{(b)}\right]^{2}
\end{gathered}
$$

Since the plate is inextensible in the $z$ direction the transverse deflection of both the top and bottom plates are the same and denoted by $w(x, y)$. That means the delamination involves combined mode II/ III or antiplane-inplane shear mode conditions. We note that this fracture mode often involves some intra-ply cracking (e.g. [135]) and near-tip matrix cracking [47] prior to delamination onset. However the investigation of the coupling between delamination onset and the former damage modes is outside the scope of this paper. The strain field for the top and bottom plates is obtained by the basic equations of linear elasticity [136]: 


$$
\begin{gathered}
\left\{\begin{array}{c}
\varepsilon_{x} \\
\varepsilon_{y} \\
\gamma_{x y}
\end{array}\right\}_{(\delta)}=\left\{\begin{array}{c}
\varepsilon_{x}^{(0)} \\
\varepsilon_{y}^{(0)} \\
\gamma_{x y}^{(0)}
\end{array}\right\}_{(\delta)}+z^{(\delta)} \cdot\left\{\begin{array}{c}
\varepsilon_{x}^{(1)} \\
\varepsilon_{y}^{(1)} \\
\gamma_{x y}^{(1)}
\end{array}\right\}_{(\delta)}+\left[z^{(\delta)}\right]^{2} \cdot\left\{\begin{array}{c}
\varepsilon_{x}^{(2)} \\
\varepsilon_{y}^{(2)} \\
\gamma_{x y}^{(2)}
\end{array}\right\}_{(\delta)} \\
\left\{\begin{array}{l}
\gamma_{x z} \\
\gamma_{y z}
\end{array}\right\}_{(\delta)}=\left\{\begin{array}{l}
\gamma_{x z}^{(0)} \\
\gamma_{y z}^{(0)}
\end{array}\right\}_{(\delta)}+z^{(\delta)} \cdot\left\{\begin{array}{l}
\gamma_{x z}^{(1)} \\
\gamma_{y z}^{(1)}
\end{array}\right\}_{(\delta)}
\end{gathered}
$$

It is also shown in Figure 1 that the shear strains $\left(\gamma_{x z}\right.$ and $\left.\gamma_{x z}\right)$ are linear functions in terms of $z^{(\delta)}$ and discontinuous at the interface plane. Based on (9)-(10) we have

$$
\begin{aligned}
& \left\{\begin{array}{c}
\varepsilon_{x}^{(1)} \\
\varepsilon_{y}^{(1)} \\
\gamma_{x y}^{(1)}
\end{array}\right\}_{(\delta)}=\left\{\begin{array}{c}
\frac{\partial \theta_{x}}{\partial x} \\
\frac{\partial \theta_{y}}{\partial y} \\
\frac{\partial \theta_{x}}{\partial y}+\frac{\partial \theta_{y}}{\partial x}
\end{array}\right\}_{(\delta)},\left\{\begin{array}{c}
\varepsilon_{x}^{(2)} \\
\varepsilon_{y}^{(2)} \\
\gamma_{x y}^{(2)}
\end{array}\right\}_{(\delta)}=\left\{\begin{array}{c}
\frac{\partial \phi_{x}}{\partial x} \\
\frac{\partial \phi_{y}}{\partial y} \\
\frac{\partial \phi_{x}}{\partial y}+\frac{\partial \phi_{y}}{\partial x}
\end{array}\right\}_{(\delta)} \\
& \left\{\begin{array}{l}
\gamma_{x z}^{(0)} \\
\gamma_{y z}^{(0)}
\end{array}\right\}_{(\delta)}=\left\{\begin{array}{c}
\theta_{x}+\frac{\partial w}{\partial x} \\
\theta_{y}+\frac{\partial w}{\partial y}
\end{array}\right\}_{(\delta)},\left\{\begin{array}{l}
\gamma_{x z}^{(1)} \\
\gamma_{y z}^{(1)}
\end{array}\right\}_{(\delta)}=2\left\{\begin{array}{l}
\phi_{x} \\
\phi_{y}
\end{array}\right\}_{(\delta)}
\end{aligned}
$$

The zeroth-order strains are different for the top and bottom plates, namely

$$
\begin{gathered}
\left\{\begin{array}{c}
\varepsilon_{x}^{(0)} \\
\varepsilon_{y}^{(0)} \\
\gamma_{x y}^{(0)}
\end{array}\right\}_{(t)}=\left\{\begin{array}{c}
\frac{\partial u_{0}}{\partial x} \\
\frac{\partial v_{0}}{\partial y} \\
\frac{\partial u_{0}}{\partial y}+\frac{\partial v_{0}}{\partial x}
\end{array}\right\}+\frac{t_{t}}{2}\left\{\begin{array}{c}
\varepsilon_{x}^{(1)} \\
\varepsilon_{y}^{(1)} \\
\gamma_{x y}^{(1)}
\end{array}\right\}_{(t)}+\frac{\left(t_{b}-t_{t}\right)}{2}\left\{\begin{array}{c}
\varepsilon_{x}^{(1)} \\
\varepsilon_{y}^{(1)} \\
\gamma_{x y}^{(1)}
\end{array}\right\}-\frac{t_{t}^{2}}{4}\left\{\begin{array}{c}
\varepsilon_{x}^{(2)} \\
\varepsilon_{y}^{(2)} \\
\gamma_{x y}^{(2)}
\end{array}\right\}_{(t)}+\frac{\left(t_{b}^{2}-t_{t}^{2}\right)}{4}\left\{\begin{array}{c}
\varepsilon_{x}^{(2)} \\
\varepsilon_{y}^{(2)} \\
\gamma_{x y}^{(2)}
\end{array}\right\}_{(b)} \\
\left\{\begin{array}{c}
\varepsilon_{x}^{(0)} \\
\varepsilon_{y}^{(0)} \\
\gamma_{x y}^{(0)}
\end{array}\right\}_{(b)}=\left\{\begin{array}{c}
\frac{\partial u_{0}}{\partial x} \\
\frac{\partial v_{0}}{\partial y} \\
\frac{\partial u_{0}}{\partial y}+\frac{\partial v_{0}}{\partial x}
\end{array}\right\}-\frac{t_{t}}{2}\left\{\begin{array}{c}
\varepsilon_{x}^{(1)} \\
\varepsilon_{y}^{(1)} \\
\gamma_{x y}^{(1)}
\end{array}\right\}-\frac{t_{t}^{2}}{4}\left\{\begin{array}{c}
\varepsilon_{x}^{(2)} \\
\varepsilon_{y}^{(2)} \\
\gamma_{x y}^{(2)}
\end{array}\right\}
\end{gathered}
$$

The relationships among the stress resultants and strain parameters of second-order plates are [91]

$$
\begin{aligned}
& \left\{\begin{array}{l}
\{N\} \\
\{M\} \\
\{L\}
\end{array}\right\}_{(\delta)}=\left[\begin{array}{lll}
{[A]} & {[B]} & {[D]} \\
{[B]} & {[D]} & {[E]} \\
{[D]} & {[E]} & {[F]}
\end{array}\right]_{(\delta)}\left\{\begin{array}{l}
\left\{\varepsilon^{(0)}\right\} \\
\left\{\varepsilon^{(1)}\right\} \\
\left\{\varepsilon^{(2)}\right\}
\end{array}\right\}_{(\delta)} \\
& \left\{\begin{array}{l}
\{Q\} \\
\{R\}
\end{array}\right\}_{(\delta)}=\left[\begin{array}{ll}
{[A]^{*}} & {[B]^{*}} \\
{[B]^{*}} & {[D]^{*}}
\end{array}\right]_{(\delta)}\left\{\begin{array}{l}
\left\{\gamma^{(0)}\right\} \\
\left\{\gamma^{(1)}\right\}
\end{array}\right\}_{(\delta)}
\end{aligned}
$$

where the matrices with superscript "*” mean the following:

$$
[.]^{*}=\left[\begin{array}{cc}
(.)_{55} & 0 \\
0 & (.)_{44}
\end{array}\right]
$$


where the dot should be replaced by $A, B$ and $D$. Moreover, $\{N\}_{(\delta)}^{\mathrm{T}}=\left\{\begin{array}{lll}N_{x} & N_{y} & N_{x y}\end{array}\right\}_{(\delta)}$ is the vector of inplane forces, $\{M\}_{(\delta)}^{\mathrm{T}}=\left\{\begin{array}{lll}M_{x} & M_{y} & M_{x y}\end{array}\right\}_{(\delta)}$ is the vector of bending and twisting moments, $\{Q\}_{(\delta)}^{\mathrm{T}}=\left\{\begin{array}{ll}Q_{x} & Q_{y}\end{array}\right\}_{(\delta)}$ is the vector of transverse shear forces, and finally $\{L\}_{(\delta)}^{\mathrm{T}}=\left\{\begin{array}{lll}L_{x} & L_{y} & L_{x y}\end{array}\right\}_{(\delta)}$ and $\{R\}_{(\delta)}^{\mathrm{T}}=\left\{\begin{array}{ll}R_{x} & R_{y}\end{array}\right\}_{(\delta)}$ are the vectors of higher-order stress resultants. The stress resultants are defined as [85]

$$
\begin{gathered}
\left\{\begin{array}{c}
N_{\alpha \beta} \\
M_{\alpha \beta} \\
L_{\alpha \beta}
\end{array}\right\}_{(\delta)}=\int_{-t / 2}^{t / 2} \sigma_{\alpha \beta(\delta)}\left\{\begin{array}{c}
1 \\
z \\
z^{2}
\end{array}\right\} d z \\
\left\{\begin{array}{l}
Q_{\alpha} \\
R_{\alpha}
\end{array}\right\}_{(\delta)}=\int_{-t / 2}^{t / 2} \sigma_{\alpha z(\delta)}\left\{\begin{array}{l}
1 \\
z
\end{array}\right\} d z
\end{gathered}
$$

where the symbols $\alpha$ and $\beta$ take $x$ and $y$. In (17)-(18) $[A],[B],[D],[E]$ and $[F]$ are the extensional, coupling, bending and higher-order stiffness matrices, and can be defined as [85]

$$
A_{i j}, B_{i j}, D_{i j}, E_{i j}, F_{i j}=\sum_{k=1}^{N_{l}} \int_{z_{k}}^{z_{k+1}} \bar{C}_{i j}^{(k)}\left(1, z, z^{2}, z^{3}, z^{4}\right) d z
$$

where $\bar{C}_{i j}^{(k)}$ is the stiffness matrix of the $k$ th laminate $[85,86]$. To derive the system of governing PDEs the total potential energy of the uncracked region should be formulated [85]. Afterwards, applying Hamilton's principle it is possible to obtain the following equations:

$$
\begin{gathered}
N_{i t, i}+N_{i j t, j}+N_{i b, i}+N_{i j b, j}=0 \\
M_{i t, i}+M_{i j t, j}+\frac{1}{2} t_{t}\left(N_{i t, i}+N_{i j t, j}\right)-Q_{i t}=0 \\
L_{i t, i}+L_{i j t, j}-\frac{1}{4} t_{t}^{2}\left(N_{i t, i}+N_{i j t, j}\right)-2 R_{i t}=0 \\
M_{i b, i}+M_{i j b, j}-\frac{1}{2} t_{t}\left(N_{i b, i}+N_{i j b, j}\right)+\frac{1}{2}\left(t_{b}-t_{t}\right)\left(N_{i t, i}+N_{i j t, j}\right)-Q_{i b}=0 \\
L_{i b, i}+L_{i j b, j}-\frac{1}{4} t_{t}^{2}\left(N_{i b, i}+N_{i j b, j}\right)+\frac{1}{4}\left(t_{b}^{2}-t_{t}^{2}\right)\left(N_{i t, i}+N_{i j t, j}\right)-2 R_{i b}=0
\end{gathered}
$$

where $i=x, j=y$ or $i=y, j=x$ leading to ten equilibrium equations. The last equation becomes

$$
Q_{x t, x}+Q_{y t, y}+Q_{x b, x}+Q_{y b, y}+q=0
$$

As can be seen the equations reveal significant coupling between the stress resultants compared to the standard SSDT [90]. Taking back (11)-(21) into (23)-(28) we obtain the governing PDE system in terms of the displacement parameters:

$$
\begin{aligned}
& \underline{M}_{1}^{\mathrm{T}} \underline{U}_{1}=0, \quad \underline{M}_{2}^{\mathrm{T}} \underline{U}_{2}=0 \\
& \underline{\underline{M}}_{i} \underline{U}_{i}=\underline{0}, \quad i=3,4, \quad \underline{M}_{5}^{\mathrm{T}} \underline{U}_{5}+q=0
\end{aligned}
$$

where $q=q(x, y)$ is the external load function, the vectors and matrices in (29) are defined in the Appendix. Analytical solution of the boundary value problem exists only for some special cases with special BCs. In the sequel the solution of a simply-supported plate is presented. 


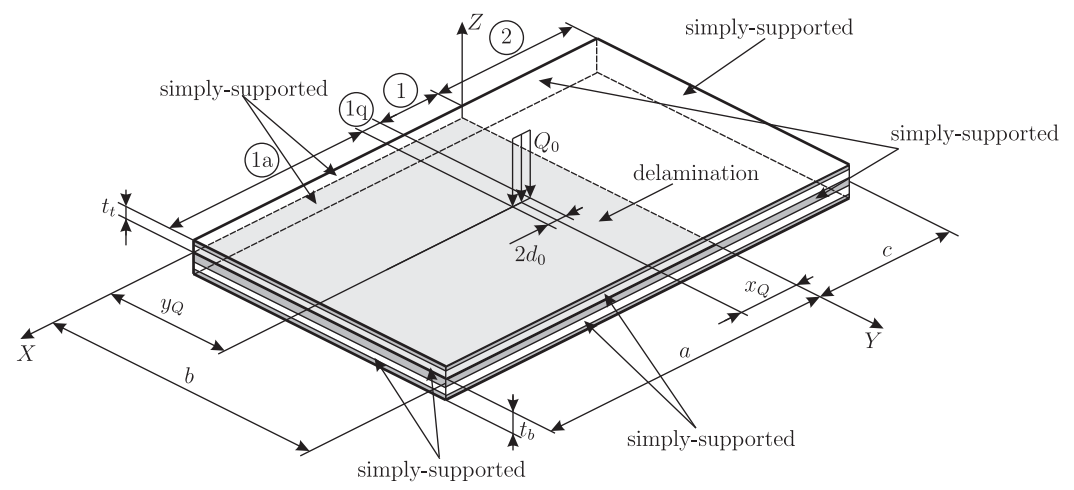

Figure 2. An unsymetrically delaminated simply supported plate subjected to point a force. Notation: (I), (I q) and ( Ia) delaminated part; (2) undelaminated part.

\section{Example: a simply supported delaminated plate}

In this section we solve the problem of a simply supported delaminated plate subjected to a point force, shown by Figure 2. The delamination is the gray rectangle in regions (1), (1q) and (1a). This problem involves bending and torsion as well as membrane deformations, and so can be assessed as a relatively complicated case. If the model is able to describe this problem accurately, then it can be assumed that it works even in simpler cases, e.g. in plates subjected to inplane loads. Apart from that in the last years several plate bending specimens have been developed for the characterization of mode-III [137] and II/ III [138] interlaminar fracture of laminated composite materials. These specimens are created with straight delamination front, i.e. the same geometry as the one considered in this work. Analytical solutions are not yet available for these specimens, and therefore the experimental tests can be evaluated only by 3D FE calculations. The plate theory solution can replace the FE models, and in a long-term course, the analytical model can be the basis to develop a shell FE for the delamination modeling of composite plates. In the problem depicted in Figure 2, the Lévy plate formulation is utilized to approximate the displacement parameters in the form of Fourier series with function coefficients $[139,140]$ :

$$
\left\{\begin{array}{l}
u_{0}(x, y) \\
v_{0}(x, y) \\
\theta_{x}(x, y) \\
\theta_{y}(x, y) \\
\phi_{x}(x, y) \\
\phi_{y}(x, y) \\
w(x, y)
\end{array}\right\}=\sum_{n=1}^{\infty}\left\{\begin{array}{c}
U_{0 n}(x) \sin \beta y \\
V_{0 n}(x) \cos \beta y \\
X_{n}(x) \sin \beta y \\
Y_{n}(x) \cos \beta y \\
T_{x n}(x) \sin \beta y \\
T_{y n}(x) \cos \beta y \\
W_{n}(x) \sin \beta y
\end{array}\right\}, \quad q=\sum_{n=1}^{\infty} Q_{n} \sin \beta y
$$

where $\beta=n \pi / b$ and $q$ is the external load. The state-space model is used to solve the system of differential equations for both the delaminated and uncracked plate portions.

\section{I Undelaminated part}

The general form of the state-space model is [85]

$$
\underline{Z}^{\prime}(u d)=\underline{T}^{(u d)} \underline{Z}^{(u d)}+\underline{F}^{(u d)}
$$

where the superscript $(u d)$ indicates the undelaminated plate portion (2) and $\underline{Z}$ is the state vector, $\underline{T}$ is the system matrix, $F$ is the vector of particular solutions. Utilizing (30) and taking it back into $\overline{\overline{(2}} 9$ ) results in a system of ODEs. The latter should be manipulated so that each equation contains the second derivative of only one displacement parameter. Then the system matrix (size $22 \times 22$ ) can be obtained. Since many papers have been published on the construction of the state-space model for similar problems $[119,131,132]$, the details are not given here. 
The state vector and the vector of particular solutions of the undelaminated part can be defined as

$$
\begin{aligned}
\underline{Z}^{(u d)}=\left(\begin{array}{ccccccccccc}
U_{0} & U_{0}^{\prime} & V_{0} & V_{0}^{\prime} & X_{n t} & X_{n t}^{\prime} & Y_{n t} & Y_{n t}^{\prime} & T_{x n t} & T_{x n t}^{\prime} & T_{y n t} \\
T_{y n t}^{\prime} & X_{n b} & X_{n b}^{\prime} & Y_{n b} & Y_{n b}^{\prime} & T_{x n b} & T_{x n b}^{\prime} & T_{y n b} & T_{y n b} & W_{n} & W_{n}^{\prime}
\end{array}\right)^{\mathrm{T}} \\
\\
\underline{F}^{(u d)}=\left[\begin{array}{llllll}
0 & \cdots & 0 & \tilde{x}_{10} Q_{n}
\end{array}\right]
\end{aligned}
$$

where $\tilde{x}_{10}$ is a constant and can be determined from the state-space model of the undelaminated part. The general solution of (31) is [85]

$$
\begin{aligned}
\underline{Z}^{(u d)}(x) & =e^{\underline{T^{(u d)}} x}\left[\underline{K}^{(u d)}+\int_{x_{0}}^{x} e^{-\underline{T}^{(u d)} \xi} \underline{F}^{(u d)}(\xi) d \xi\right] \\
& =\underline{\underline{G}}^{(u d)}(x) \underline{K}^{(u d)}+\underline{H}^{(u d)}(x)
\end{aligned}
$$

where $\underline{K}$ is the vector of constants (22).

\subsection{Delaminated part}

The state-space model of the delaminated portion ((1), (1q) and (1a)) can be derived relatively simply based on [129]. The equilibrium equations of standard SSDT [90] can be used, however since the deflection of the top and bottom plates are the same there is a coupling between the shear forces of the top and bottom plates, namely (28) applies also to the delaminated portion. The system matrix of the delaminated portion is a $26 \times 26$ matrix. The delaminated part was divided into three subparts in Figure 2: (1), (1q) with uniformly distributed line load along distance $d_{0}$, which was relatively short and finally (1a). The state-space model was formulated for each subparts and the kinematic and dynamic continuity is established among them.

\section{Boundary and continuity conditions}

The elements of the state vector in (32) and that of the delaminated part can be referred to as

$$
\begin{gathered}
Z_{i}^{(u d)}=\sum_{j=1}^{22} G_{i j}^{(u d)} K_{j}^{(u d)}+H_{j}^{(u d)} \\
Z_{i}^{(d)}=\sum_{j=1}^{26} G_{i j}^{(d)} K_{j}^{(d)}+H_{j}^{(d)}
\end{gathered}
$$

In accordance with Figure 2, we have four different plate portions. Thus, the four subparts are denoted by (1a), (1q), (1) for the delaminated portion and (2) for the undelaminated region, respectively. The point force causes singularity in the PDEs, therefore a plate portion (1q) loaded by a constant line force was applied, the length $d_{0}$ was a very small value compared to the plate dimensions. In this case $Q_{n}=2 Q_{0} / b \sin \left(\beta y_{Q}\right)$ [85], which was applied in the portion (1q), where $Q_{0}=500 \mathrm{~N} / \mathrm{mm}$ in accordance with Figure 2. If $d_{0}=1 \mathrm{~mm}$ then the resultant force is exactly $1000 \mathrm{~N}$. The BCs are formulated through the displacement parameters and the stress resultants. The latter ones can be expressed in the following forms:

$$
\left\{\begin{array}{c}
N_{x}, L_{x} \\
N_{y}, L_{y} \\
M_{x}, Q_{x} \\
M_{y}, R_{x}
\end{array}\right\}_{(\delta)}=\sum_{n=1}^{\infty}\left\{\begin{array}{c}
n_{x n}, l_{x n} \\
n_{y n}, l_{y n} \\
m_{x n}, q_{x n} \\
m_{y n}, r_{x n}
\end{array}\right\} \quad \sin \beta y
$$




$$
\left\{\begin{array}{c}
N_{x y} \\
M_{x y} \\
Q_{y} \\
R_{y}
\end{array}\right\}_{(\delta)}=\sum_{n=1}^{\infty}\left\{\begin{array}{c}
n_{x y n} \\
m_{x y n} \\
q_{y n} \\
r_{y n}
\end{array}\right\}_{(\delta)} \cos \beta y
$$

i.e. $n_{x n}$ is the function coefficient in the Fourier series of $N_{x}$, etc. For the present problem 100 conditions need be formulated. Based on Figure 2 and the coupling among the stress resultants in the equilibrium equations (23)-(28) the BCs are

$$
\begin{gathered}
W_{n}^{(1 a)}(a)=0, V_{0 n \delta}^{(1 a)}(a)=0, Y_{n \delta}^{(1 a)}(a)=0, T_{y n \delta}^{(1 a)}(a)=0 \\
m_{x n \delta}^{(1 a)}(a)=0, n_{x y n \delta}^{(1 a)}(a)=0, l_{x y n \delta}^{(1 a)}(a)=0 \\
W_{n}^{(2)}(-c)=0, V_{0}^{(2)}(-c)=0, Y_{n \delta}^{(2)}(-c)=0, T_{y n \delta}^{(2)}(-c)=0 \\
n_{x n t}^{(2)}+\left.n_{x n b}^{(2)}\right|_{x=-c}=0 \\
m_{x n t}^{(2)}+\left.\frac{1}{2} t_{t} n_{x n t}^{(2)}\right|_{x=-c}=0, m_{x n b}^{(2)}-\frac{1}{2} t_{b} n_{x n b}^{(2)}-\left.\frac{1}{2}\left(t_{b}-t_{t}\right) n_{x n t}^{(2)}\right|_{x=-c}=0 \\
l_{x n t}^{(2)}-\left.\frac{1}{4} t_{t}^{2} n_{x n t}^{(2)}\right|_{x=-c}=0, l_{x n b}^{(2)}-\frac{1}{4} t_{t}^{2} n_{x n b}^{(2)}-\left.\frac{1}{4}\left(t_{b}^{2}-t_{t}^{2}\right) n_{x n t}^{(2)}\right|_{x=-c}=0
\end{gathered}
$$

where $\delta$ can take $t$ and $b$, and so some of the equations involve two conditions, altogether we have 24 BCs. The continuity conditions for the displacement parameters between regions (1) and (2) are (by considering (9)-(10)):

$$
\begin{aligned}
& U_{0 n t}^{(1)}(0)=U_{0 n}^{(2)}+\frac{1}{2}\left(t_{t} X_{n t}^{(2)}+\left(t_{b}-t_{t}\right) X_{n b}^{(2)}\right)-\left.\frac{1}{4}\left(t_{t}^{2} T_{x n t}^{(2)}+\left(t_{b}^{2}-t_{t}^{2}\right) T_{x n b}^{(2)}\right)\right|_{x=0} \\
& U_{0 n b}^{(1)}(0)=U_{0 n}^{(2)}-\frac{1}{2} t_{t} X_{n b}^{(2)}-\left.\frac{1}{4} t_{t}^{2} T_{x n b}^{(2)}\right|_{x=0} \\
& V_{0 n t}^{(1)}(0)=V_{0 n}^{(2)}+\frac{1}{2}\left(t_{t} Y_{n t}^{(2)}+\left(t_{b}-t_{t}\right) Y_{n b}^{(2)}\right)-\left.\frac{1}{4}\left(t_{t}^{2} T_{y n t}^{(2)}+\left(t_{b}^{2}-t_{t}^{2}\right) T_{y n b}^{(2)}\right)\right|_{x=0} \\
& V_{0 n b}^{(1)}(0)=V_{0 n}^{(2)}-\frac{1}{2} t_{t} Y_{n b}^{(2)}-\left.\frac{1}{4} t_{t}^{2} T_{y n b}^{(2)}\right|_{x=0} \\
& X_{n \delta}^{(1)}(0)=X_{n \delta}^{(2)}(0), Y_{n \delta}^{(1)}(0)=Y_{n \delta}^{(2)}(0) \\
& T_{x n \delta}^{(1)}(0)=T_{x n \delta}^{(2)}(0), T_{y n \delta}^{(1)}(0)=T_{y n \delta}^{(2)}(0) \\
& W_{n}^{(1)}(0)=W_{n}^{(2)}(0), W_{n}^{\prime(1)}(0)=W_{n}^{\prime(2)}(0)
\end{aligned}
$$

The consideration of the coupling among the stress resultants based on the equilibrium equations (23)(28) yields

$$
\begin{gathered}
n_{x n t}^{(1)}+\left.n_{x n b}^{(1)}\right|_{x=0}=n_{x n t}^{(2)}+\left.n_{x n b}^{(2)}\right|_{x=0}, n_{x y n t}^{(1)}+\left.n_{x y n b}^{(1)}\right|_{x=0}=n_{x y n t}^{(2)}+\left.n_{x y n b}^{(2)}\right|_{x=0} \\
l_{x n t}^{(1)}(0)=l_{x n t}^{(2)}-\left.\frac{1}{4} t_{t}^{2} n_{x n t}^{(2)}\right|_{x=0}, l_{x y n t}^{(1)}(0)=l_{x y n t}^{(2)}-\left.\frac{1}{4} t_{t}^{2} n_{x y n t}^{(2)}\right|_{x=0}
\end{gathered}
$$




$$
\begin{aligned}
& l_{x n b}^{(1)}(0)=l_{x n b}^{(2)}-\frac{1}{4} t_{t}^{2} n_{x n b}^{(2)}+\left.\frac{1}{4}\left(t_{b}^{2}-t_{t}^{2}\right) n_{x n t}^{(2)}\right|_{x=0} \\
& l_{x y n b}^{(1)}(0)=l_{x y n b}^{(2)}-\frac{1}{4} t_{t}^{2} n_{x y n b}^{(2)}+\left.\frac{1}{4}\left(t_{b}^{2}-t_{t}^{2}\right) n_{x y n t}^{(2)}\right|_{x=0} \\
& m_{x n t}^{(1)}(0)=m_{x n t}^{(2)}+\left.\frac{1}{2} t_{t} n_{x n t}^{(2)}\right|_{x=0} \\
& m_{x n b}^{(1)}(0)=m_{x n b}^{(2)}-\frac{1}{2} t_{t} n_{x n b}^{(2)}+\left.\frac{1}{2}\left(t_{b}-t_{t}\right) n_{x n t}^{(2)}\right|_{x=0} \\
& m_{x y n t}^{(1)}(0)=m_{x y n t}^{(2)}+\left.\frac{1}{2} t_{t} n_{x y n t}^{(2)}\right|_{x=0} \\
& m_{x y n b}^{(1)}(0)=m_{x y n b}^{(2)}-\frac{1}{2} t_{t} n_{x y n b}^{(2)}+\left.\frac{1}{2}\left(t_{b}-t_{t}\right) n_{x y n t}^{(2)}\right|_{x=0}
\end{aligned}
$$

We can formulate 24 continuity conditions between regions (1) and (2). The continuity between the (1) and (1q) portions involves the following 26 conditions:

$$
\begin{aligned}
& \left.\left(U_{0 n \delta}, V_{0 n \delta}, X_{n \delta}, Y_{n \delta}, T_{x n \delta}, T_{y n \delta}, W_{n}, W_{n}^{\prime}\right)\right|_{x=x_{01}} ^{(1)}= \\
& \left.\left(U_{0 n \delta}, V_{0 n \delta}, X_{n \delta}, Y_{n \delta}, T_{x n \delta}, T_{y n \delta}, W_{n}, W_{n}^{\prime}\right)\right|_{x=x_{01}} ^{(1 q)} \\
& \left.\left(n_{x n \delta}, n_{x y n \delta}, m_{x n \delta}, m_{x y n \delta}, l_{x n \delta}, l_{x y n \delta}\right)\right|_{x=x_{01}} ^{(1)}= \\
& \left.\left(n_{x n \delta}, n_{x y n \delta}, m_{x n \delta}, m_{x y n \delta}, l_{x n \delta}, l_{x y n \delta}\right)\right|_{x=x_{01}} ^{(1 q)}
\end{aligned}
$$

where $x_{01}=x_{Q}-d_{0}$. A further 26 conditions can be derived between (1q) and (1a), these are similar to those in (52), therefore these are not presented here. We have $24+24+26+26=100$ conditions altogether.

\section{Calculation of the J-integral}

In the general $3 \mathrm{D}$ case the $J$-integral is $[141,142]$

$$
J_{k}=\int_{C}\left(W n_{k}-\sigma_{i j} u_{i, k} n_{j}\right) d s-\int_{A}\left(\sigma_{i 3} u_{i, k}\right)_{, 3} d A, \quad k=1,2,3
$$

where in accordance with Figure $3 n_{k}$ is the outward normal vector of the contour $C, \sigma_{i j}$ is the stress tensor ( $\sigma_{i j} n_{j}$ is the traction vector), $u_{i}$ is the displacement vector, $A$ is the area enclosed by contour $C$ and finally $W$ is the strain energy density. The contour $C$ contains the crack tip and the integration is carried out in the counterclockwise direction (see e.g. [143]). The contour $C$ is defined in the form of a zero-area path [125], this results in the fact that the surface integral in (53) becomes zero. In our case $x_{1}=x$, $x_{2}=z$ and $x_{3}=y$. The total $J$-integral involves the sum of the products of the stress resultants and strains evaluated at the locations of $x=-0$ and $x=+0$. It has already been shown that under mixedmode II/III conditions the shear forces and the higher-order stress resultants, $R_{x}$ and $R_{y}$ do not contribute to the ERR at all. For second-order plates with symmetric lay-up and midplane delamination the total $J$ has been presented in [129]. Therefore, we do not present the details of the calculation. The mode-II and mode-III $J$-integrals can be separated simply by separating the terms with respect to the $\sin$ (mode-II) and $\cos$ (mode-III) functions leading to 


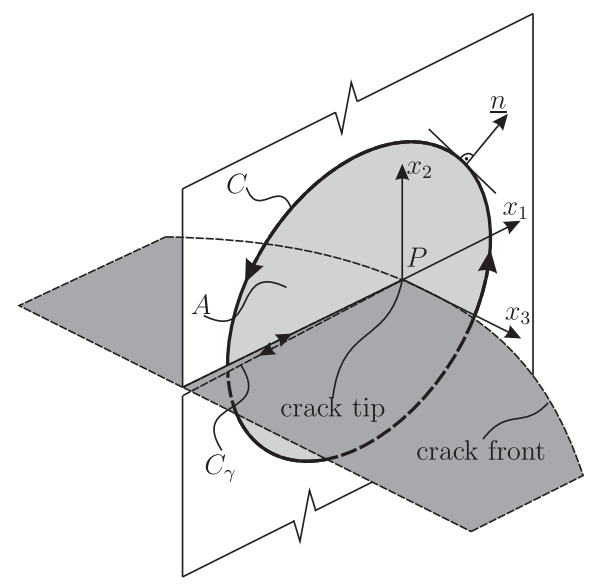

Figure 3. Reference system for the 3D J-integral.

$$
\begin{gathered}
J_{I I}=\frac{1}{2} \sum_{\delta=b, t}\left\{\left(\left.N_{x 1 \delta} \varepsilon_{x 1 \delta}^{(0)}\right|_{x=+0}-\left.N_{x 2 \delta} \varepsilon_{x 2 \delta}^{(0)}\right|_{x=-0}\right)-\left(\left.N_{y 1 \delta} \varepsilon_{y 1 \delta}^{(0)}\right|_{x=+0}-\left.N_{y 2 \delta} \varepsilon_{y 2 \delta}^{(0)}\right|_{x=-0}\right)\right. \\
+\left(\left.M_{x 1 \delta} \varepsilon_{x 1 \delta}^{(1)}\right|_{x=+0}-\left.M_{x 2 \delta} \varepsilon_{x 2 \delta}^{(1)}\right|_{x=-0}\right)-\left(\left.M_{y 1 \delta} \varepsilon_{y 1 \delta}^{(1)}\right|_{x=+0}-\left.M_{y 2 \delta} \varepsilon_{y 2 \delta}^{(1)}\right|_{x=-0}\right) \\
\left.+\left(\left.L_{x 1 \delta} \varepsilon_{x 1 \delta}^{(2)}\right|_{x=+0}-\left.L_{x 2 \delta} \varepsilon_{x 2 \delta}^{(2)}\right|_{x=-0}\right)-\left(\left.L_{y 1 \delta} \varepsilon_{y 1 \delta}^{(2)}\right|_{x=+0}-\left.L_{y 2 \delta} \varepsilon_{y 2 \delta}^{(2)}\right|_{x=-0}\right)\right\} \\
J_{I I I}=\frac{1}{2} \sum_{\delta=b, t}\left\{\left(\left.N_{x y 1 \delta} \hat{\gamma}_{x y 1 \delta}^{(0)}\right|_{x=+0}-\left.N_{x y 2 \delta} \hat{\gamma}_{x y 2 \delta}^{(0)}\right|_{x=-0}\right)+\left(\left.M_{x y 1 \delta} \hat{\gamma}_{x y 1 \delta}^{(1)}\right|_{x=+0}-\left.M_{x y 2 \delta} \hat{\gamma}_{x y 2 \delta}^{(1)}\right|_{x=-0}\right)\right. \\
\left.+\left(\left.L_{x y 1 \delta} \hat{\gamma}_{x y 1 \delta}^{(2)}\right|_{x=+0}-\left.L_{x y 2 \delta} \hat{\gamma}_{x y 2 \delta}^{(2)}\right|_{x=-0}\right)\right\}
\end{gathered}
$$

where the shear strains with the hat are defined as

$$
\hat{\gamma}_{x y}^{(0)}=\frac{\partial u_{0}}{\partial y}-\frac{\partial v_{0}}{\partial x}, \hat{\gamma}_{x y}^{(1)}=\frac{\partial \theta_{x}}{\partial y}-\frac{\partial \theta_{y}}{\partial x}, \hat{\gamma}_{x y}^{(2)}=\frac{\partial \phi_{x}}{\partial y}-\frac{\partial \phi_{y}}{\partial x}
$$

As can be seen, the $J$-integrals are not contributed to by the shear forces and the higher-order stress resultants denoted by $R$ at all. The reason for that is these stress resultants and the corresponding shear strains are continuous across the delamination front. In (54)-(55) the subscript (1) refers to the stress resultants and strain components of region (1) in Figure 2, while subscript (2) refers to the undelaminated region (2). The latter ones were calculated based on Sections 3-5, and we highlight again that the equations for the delaminated part are not detailed here, but these can be derived based on the literature $[90,91,133,134]$. It is very important to note that the stiffness parameters $(22)$ of the top and bottom plates are calculated with respect to the local reference planes and the stiffness of the undelaminated top/bottom plate is the same as that of the delaminated top/bottom plate. The stiffnesses are independent of the global reference plane of the system, the latter was implemented into the displacement field through (2), and so the transformation of the stiffness parameters is performed through the equilibrium equations.

\section{Results and discussion}

The properties of the analyzed simply-supported plate were (refer to Figure 2): $a=105 \mathrm{~mm}$ (crack length), $c=45 \mathrm{~mm}$ (uncracked length), $b=100 \mathrm{~mm}$ and $b=160 \mathrm{~mm}$ (plate width), $t_{t}+t_{b}=4.5 \mathrm{~mm}$ (plate thickness), $q_{0}=1000 \mathrm{~N}$ (point force magnitude, $q_{0}=2 Q_{0} d_{0}$ ), $x_{Q}=31 \mathrm{~mm}, y_{Q}=50 \mathrm{~mm}$ (point of action coordinates of the resultant of $Q_{0}$ ) and $d_{0}=1 \mathrm{~mm}$. The plate is made of a carbon/epoxy material, the lay-up of the uncracked part was $\left[ \pm 45_{2}^{f} / 0 / \pm 45_{2}^{f} / \overline{0}\right]$ including nine layers altogether. A single layer 
Table I. Elastic properties of single carbon/epoxy composite laminates.

\begin{tabular}{llllllllll}
\hline & $E_{x}[\mathrm{GPa}]$ & $E_{y}[\mathrm{GPa}]$ & $E_{z}[\mathrm{GPa}]$ & $G_{y z}[\mathrm{GPa}]$ & $G_{x z}[\mathrm{GPa}]$ & $G_{x y}[\mathrm{GPa}]$ & $\nu_{y z}[-]$ & $\nu_{x z}[-]$ & $\nu_{x y}[-]$ \\
\hline $\pm 45^{\circ}$ & 16.39 & 16.39 & 16.4 & 5.46 & 5.46 & 16.4 & 0.5 & 0.5 & 0.3 \\
$0^{\circ}$ & 148 & 9.65 & 9.65 & 4.91 & 4.66 & 3.71 & 0.27 & 0.25 & 0.3 \\
\hline
\end{tabular}

was $0.5 \mathrm{~mm}$ thick. The properties of the individual laminae are given by Table 1 (see also [86]). Four different positions of the delamination in the through thickness direction was studied, these were assigned as cases I, II, III and IV (see the subsequent figures).

The computation was performed in the code MAPLE [144] in accordance with the following points. The stiffness matrices of each single layer of the plate were determined based on the elastic properties of the laminates given in Table 1. The problem in Figure 2 was solved varying the number of Fourier series terms $(N)$ by creating a for-do cycle. Based on the displacement parameters the stress resultants and the stresses were calculated. Finally the ERRs were calculated using the $J$-integral. The convergence of the results was analyzed and it was found that after the 13th Fourier term there was no change in the displacement field, stresses, forces and ERRs.

\section{I FE model}

In order to verify the analytical results FE analyses were carried out. The 3D FE models of the plate with different delamination positions in the through thickness direction were created in the code ANSYS 12 using 8-node linear solid elements. Similar 3D models are documented in the literature [145], therefore the model is not shown here. The global element size was $0.25 \mathrm{~mm} \times 0.25 \mathrm{~mm} \times 2.0 \mathrm{~mm}$, i.e. each layer was modeled by two elements in the through-thickness direction. In the vicinity of the crack tip a refined mesh was constructed including trapezoid shape elements [145]. The $z$ displacements of the contact nodes over the delaminated surface were imposed to be the same. The mode-II and mode-III ERRs were calculated by the virtual crack closure technique (VCCT) (e.g. [146]), the size of the crack tip elements were $\Delta x=0.25 \mathrm{~mm}, \Delta y=0.25 \mathrm{~mm}$ and $\Delta z=2 \mathrm{~mm}$. For the determination of $G_{I I}$ and $G_{I I I}$ along the delamination front a so-called MACRO was written in the ANSYS Design and Parametric Language (ADPL). The MACRO gets the nodal forces and displacements at the crack tip and at each pair of nodes, respectively, then by defining the size of crack tip elements it determines and plots the ERRs at each node along the crack front.

\subsection{Displacement and stress distributions}

To demonstrate the applicability of the present model the distribution of inplane displacement components and the stresses are plotted in the through thickness direction. The stresses were calculated by the layerwise stress-strain relationships [85]. Altogether eight different computations were carried out: four different positions of the delamination in the thickness direction were applied (see later), at the same time each case was calculated for two different plate widths: $b=100$ and $b=160 \mathrm{~mm}$ (refer to Figure 2), respectively. However, not all these cases are documented in this paper, refer to the legend in each figure. The displacement and stress distributions were plotted in the vicinity of certain points located on the delamination front. In each case the results by SSDT, FE solution and by FSDT [131] are presented. Figure 5 shows the results obtained in case I, when the delamination was between the $\pm 45_{f}^{\circ}$ and the $0^{\circ}$ plies (see the left-hand side of the figure). It can be seen, that there is an offset in the $u$ displacement component by FE and analytical (SSDT and FSDT) solutions. The reason for that is the boundary conditions in the $X-Y$ plane can be given definitely in ANSYS, but can not in the analytical model. In contrast, the neutral plane with respect to $v$ coincides almost to the midplane of the plate. For both displacement components there is a very moderate nonlinearity over the thickness direction. Moreover, it is seen that there is apparently no difference between the SSDT and FSDT solutions in this case. The slopes of the analytical and FE solutions in case I for the inplane displacements are collected in Table 2. The displacements by FEM of the top and bottom subparts were fitted by a linear and a quadratic 
Table 2. Comparison of the slopes of displacement distributions in Figure 4, case I, $b=160 \mathrm{~mm}$.

\begin{tabular}{|c|c|c|c|c|c|}
\hline \multicolumn{2}{|c|}{ slope } & \multirow{2}{*}{$\frac{\text { FSDT }}{0.0451}$} & \multirow{2}{*}{$\frac{\text { SSDT }}{0.0451-0.000117 z^{(t)}}$} & \multirow{2}{*}{$\frac{\text { FEM ( } u \text { and } v \text { are linear) }}{0.0442}$} & \multirow{2}{*}{$\frac{\text { FEM ( } u \text { and } v \text { are quadratic) }}{0.0442+0.001174 z^{(t)}}$} \\
\hline \multicolumn{2}{|c|}{$\frac{\partial u_{\text {top }}}{\partial z^{(t)}} \mid x=0$} & & & & \\
\hline$\frac{\partial u_{\text {bot }}}{\partial z^{(b)}}$ & $\begin{array}{l}y=b / 2 \\
x=0\end{array}$ & 0.0454 & $0.0454+0.000486 z^{(b)}$ & 0.0446 & $0.0446-0.000400 z^{(b)}$ \\
\hline \multirow{2}{*}{$\begin{array}{l}\frac{\partial v_{\text {top }}}{\partial z^{(t)}} \\
\frac{\partial v_{b o t}}{\partial z^{(b)}}\end{array}$} & $\begin{array}{l}y=b / 2 \\
x=0\end{array}$ & -0.0284 & $-0.0287-0.00162 z^{(t)}$ & -0.0311 & $-0.0311-0.001274 z^{(t)}$ \\
\hline & $\begin{array}{l}y=b \\
x=0 \\
y=b\end{array}$ & -0.0280 & $-0.0284+0.00194 z^{(b)}$ & -0.0317 & $-0.0317+0.002718 z^{(b)}$ \\
\hline
\end{tabular}
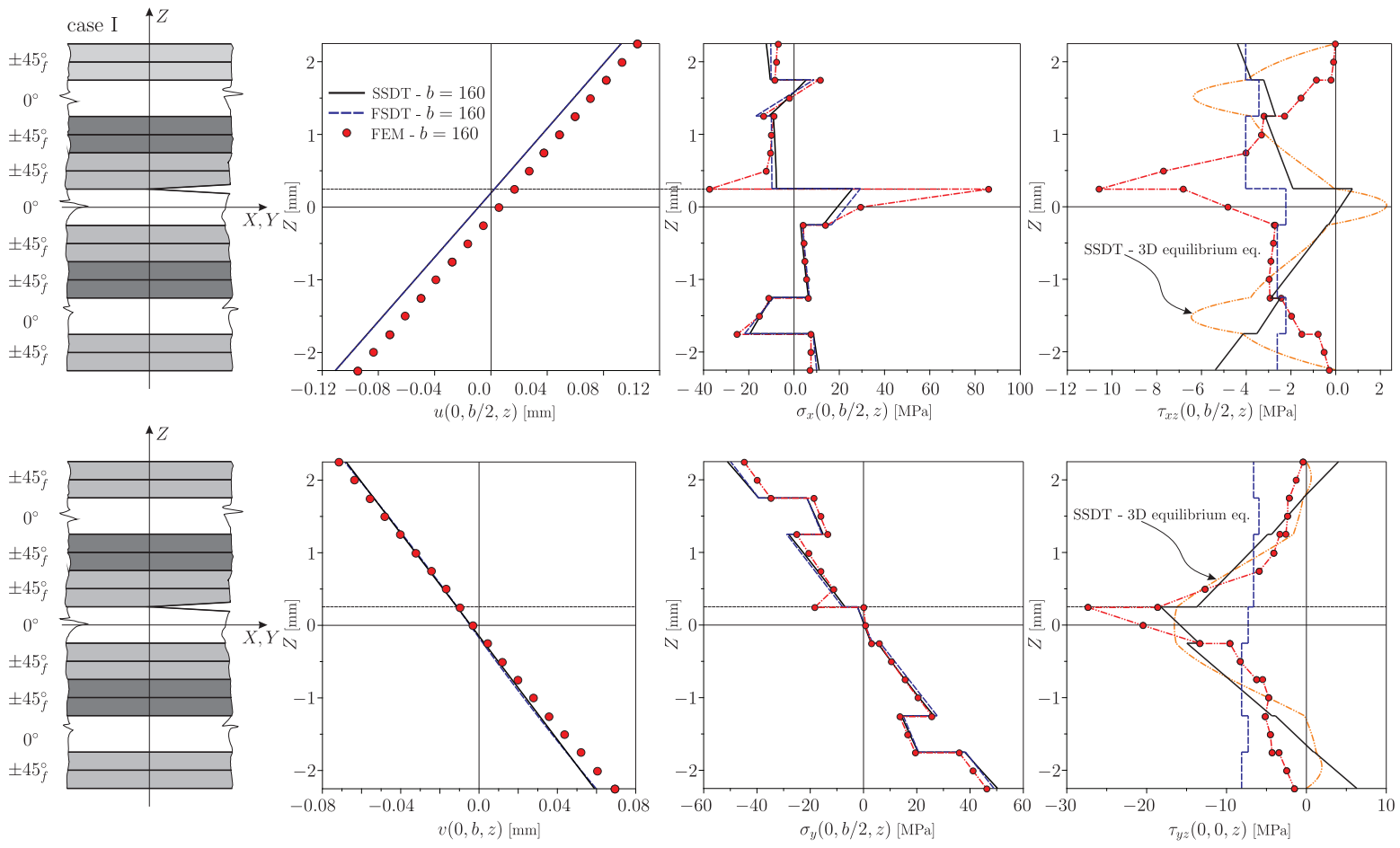

Figure 4. Distribution of the inplane displacements $(u$ and $v)$, normal stresses $\left(\sigma_{x}\right.$ and $\left.\sigma_{y}\right)$ and shear stresses $\left(\tau_{x z}\right.$ and $\left.\tau_{y z}\right)$ over the plate thickness for case I.

function in the local (top and bottom) coordinate systems. The constant parts of the slopes agree excellently. Taking the FE solution to be the reference value, the difference between the constant part by analysis and FEM are within 5\% for $u$ and $9 \%$ for $v$, respectively. In the case of the linear parts of slopes by $\mathrm{SSDT}$ and $\mathrm{FE}$ the differences are much bigger.

The normal stresses $\left(\sigma_{x}\right.$ and $\left.\sigma_{y}\right)$ were calculated along a line determined by the midpoint of the delamination front. An important observation is that the stress distribution is asymmetric in accordance with both plate theory and FE solution (Figure 4). The FE model gives nodal stresses, which is the average of the adjacent element stresses. Therefore, the normal stresses in the delamination front were calculated by taking the average of the values by SSDT and FSDT in regions (1) and (2). The numerical and analytical results agree good, except in the delamination plane, where the numerical model predicts higher stresses because of the singular nature of the stress field. It was shown in a recent paper [129] that for symmetrically delaminated plates the SSDT agrees better with the results of a FE model built-up from linear elements. The normal stresses by SSDT and FSDT are very close to each other. Considering 

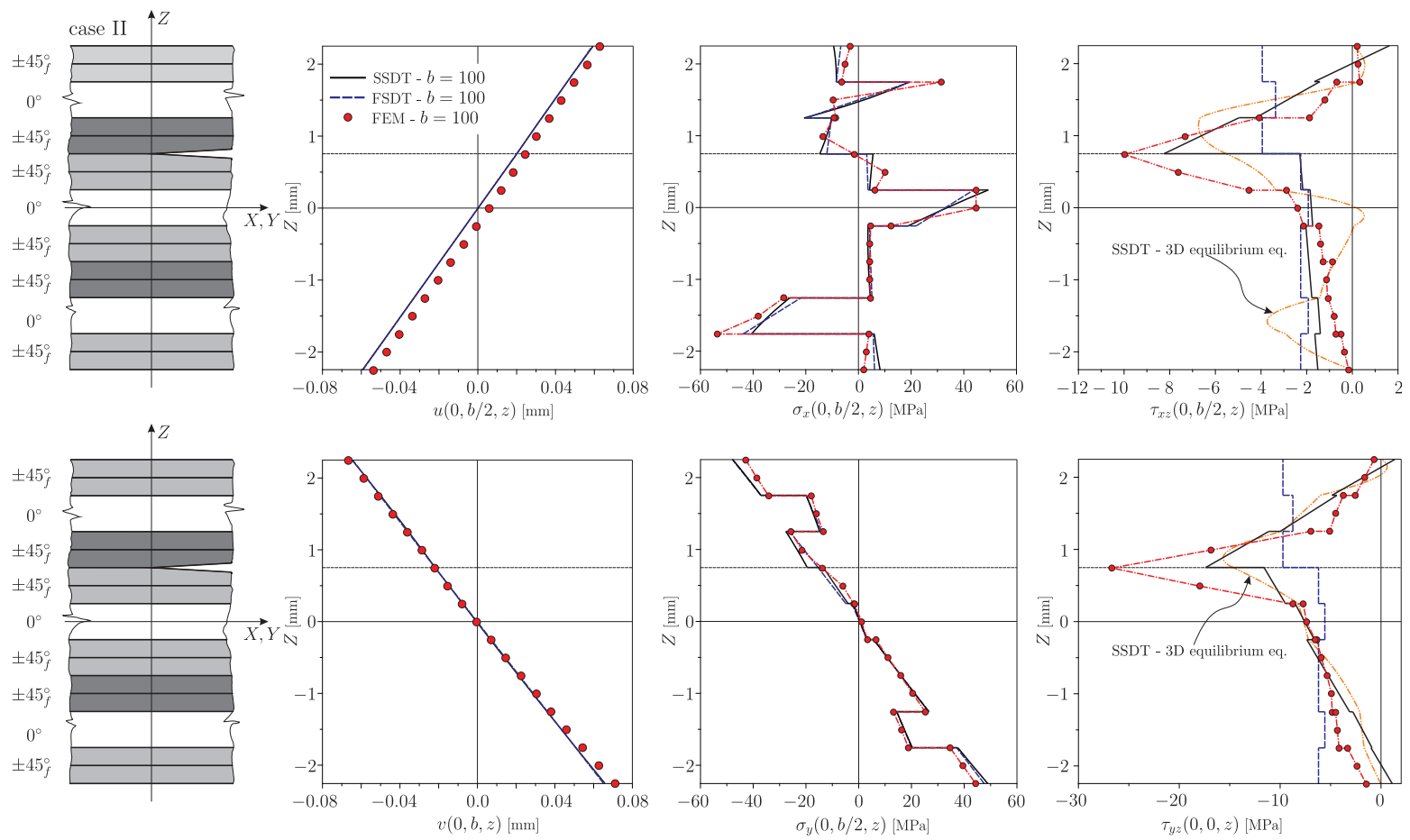

Figure 5. Distribution of the inplane displacements $(u$ and $v)$, normal stresses $\left(\sigma_{x}\right.$ and $\left.\sigma_{y}\right)$ and shear stresses $\left(\tau_{x z}\right.$ and $\left.\tau_{y z}\right)$ over the plate thickness for case II.

Table 3. Comparison of the slopes of displacement distributions in Figure 5 , case $I 1, b=100 \mathrm{~mm}$.

\begin{tabular}{|c|c|c|c|c|c|}
\hline & & FSDT & SSDT & FEM ( $u$ and $v$ are linear) & FEM ( $u$ and $v$ are quadratic) \\
\hline$\frac{\partial u_{t o p}}{\partial z^{(t)}}$ & $x=0$ & 0.0260 & $0.0262+0.00120 z^{(t)}$ & 0.0257 & $0.0257+0.000183 z^{(t)}$ \\
\hline$\frac{\partial u_{b o t}}{\partial z^{(b)}}$ & $\begin{array}{l}y=b / 2 \\
x=0\end{array}$ & 0.0264 & $0.0265-0.000048 z^{(b)}$ & 0.0261 & $0.0261-0.000616 z^{(b)}$ \\
\hline$\frac{\partial v_{t o p}}{\partial z^{(t)}}$ & $\begin{array}{l}y=b / 2 \\
x=0\end{array}$ & -0.0283 & $-0.0287-0.00229 z^{(t)}$ & -0.0298 & $-0.0298-0.002512 z^{(t)}$ \\
\hline$\frac{\partial v_{b o t}}{\partial z^{(b)}} \mid$ & $\begin{array}{l}y=b \\
x=0 \\
y=b\end{array}$ & -0.0289 & $-0.0292-0.02916 z^{(b)}$ & -0.0311 & $-0.0311-0.00191 z^{(b)}$ \\
\hline
\end{tabular}

the shear stresses $\left(\tau_{x z}, \tau_{y z}\right)$ by FE solution a sharp peak appears at the position of the delamination and the traction-free surface conditions are fairly satisfied. In contrast, the FSDT predicts piecewise constant, the SSDT predicts piecewise linear distributions, and neither one satisfies the traction-free conditions at the top and bottom boundaries. However, the transverse shear stresses can be calculated by integrating the $3 \mathrm{D}$ equilibrium equations $(\underline{\underline{\sigma}} \cdot \nabla=0)[65,85]$. By imposing traction-free top and bottom boundaries as well as stress continuity between the layers it is possible to obtain the dashed-dot-dot (orange) curves in Figure 4. It can be seen that this solution is rather closer to the piecewise linear SSDT solution than the FE stress distribution. Without any doubt the SSDT theory is much better in the approximation of interlaminar shear stresses than FSDT, especially in the case of $\tau_{y z}$. For case II the results are shown by Figure 5 indicating similar differences in the displacements to those for case I. Consequently, the slopes of the inplane displacements, collected in Table 3, are similar to those by Table 2, involving the same conclusions. This trend holds even for cases III and IV, therefore the displacement slopes related to these cases are not discussed at all. In the $\sigma_{x}$ normal stress distribution a large peak takes place in the $0^{\circ}$ plies in accordance with FE model, which is followed well by the FSDT and SSDT. For $\sigma_{y}$ the agreement is excellent. Finally for the shear stresses the sharp peaks appear again in 

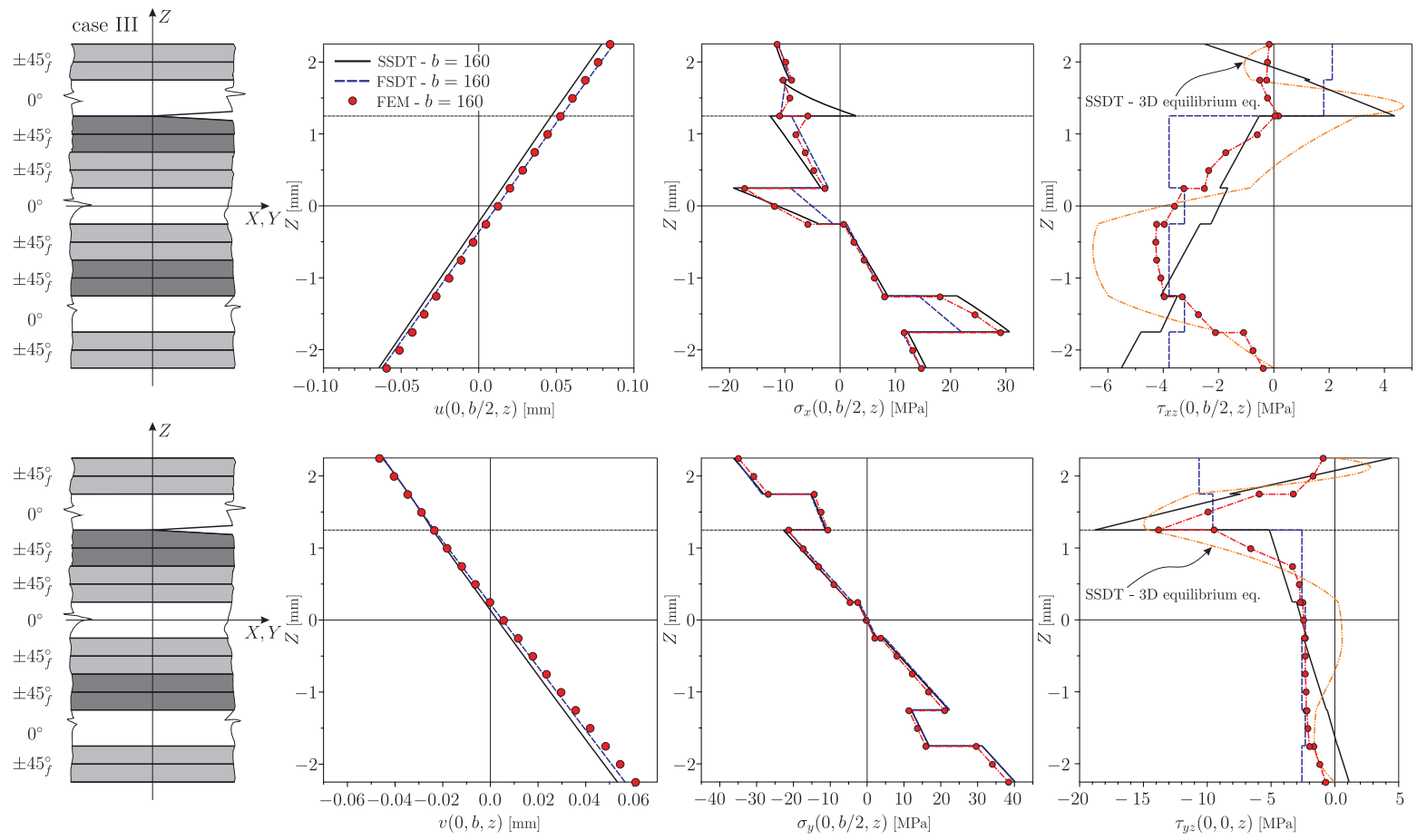

Figure 6. Distribution of the inplane displacements $(u$ and $v)$, normal stresses $\left(\sigma_{x}\right.$ and $\left.\sigma_{y}\right)$ and shear stresses $\left(\tau_{x z}\right.$ and $\left.\tau_{y z}\right)$ over the plate thickness for case III.
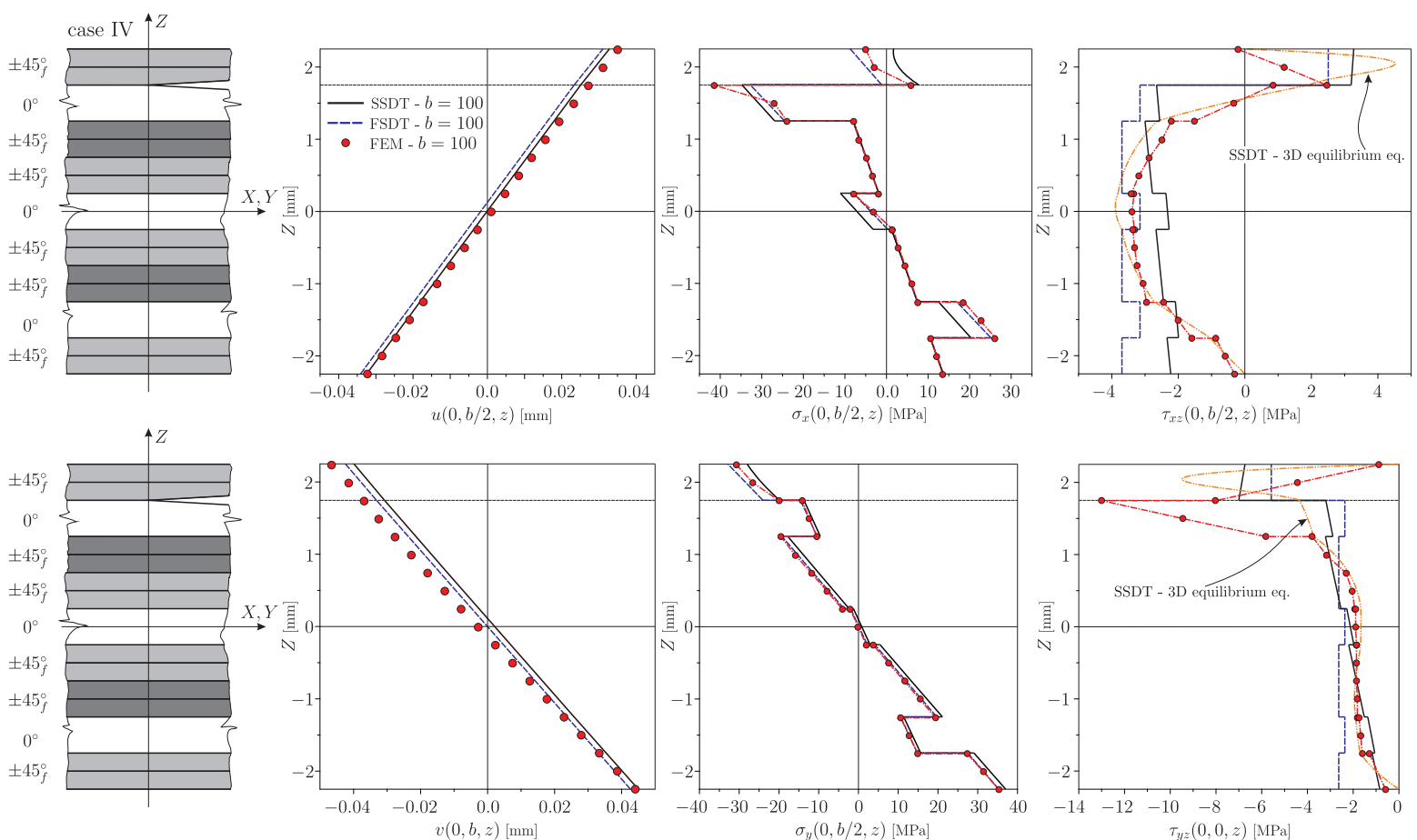

Figure 7. Distribution of the inplane displacements $\left(u\right.$ and $v$ ), normal stresses $\left(\sigma_{x}\right.$ and $\left.\sigma_{y}\right)$ and shear stresses $\left(\tau_{x z}\right.$ and $\left.\tau_{y z}\right)$ over the plate thickness for case IV.

the plane of the delamination. The shear stress distributions by the integration of the 3D equilibrium equations are plotted again. For cases III and IV the results are summarized in Figures 6 and 7. In these 
case I

$b=100 \mathrm{~mm}$
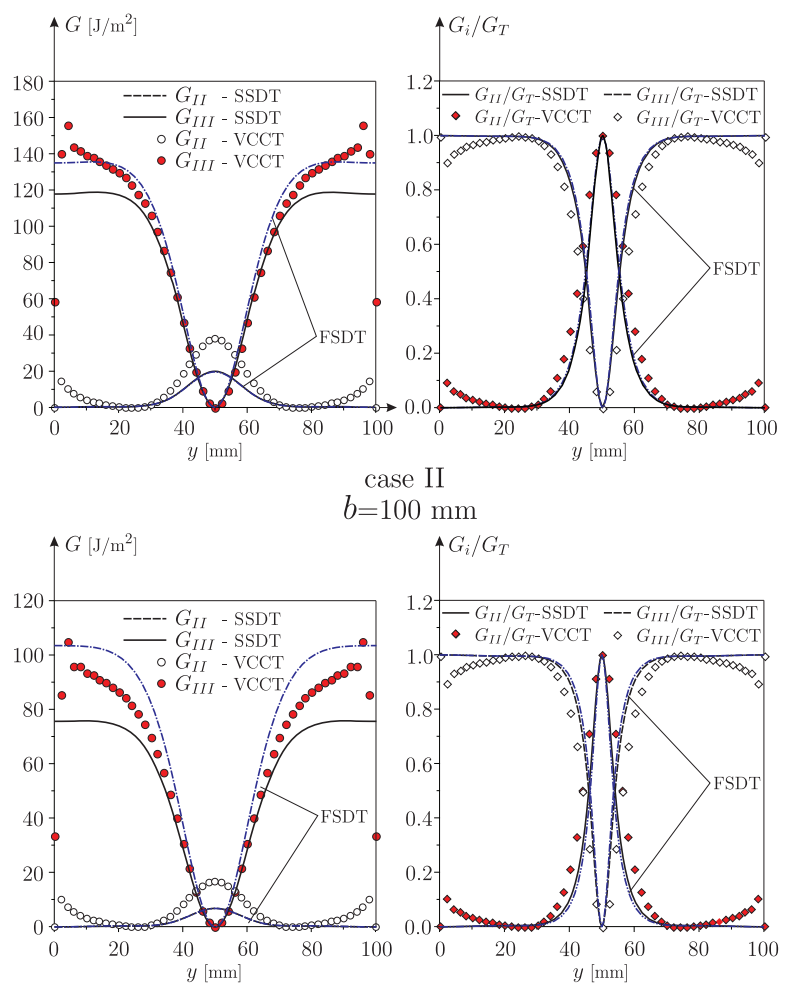

case I

$b=160 \mathrm{~mm}$

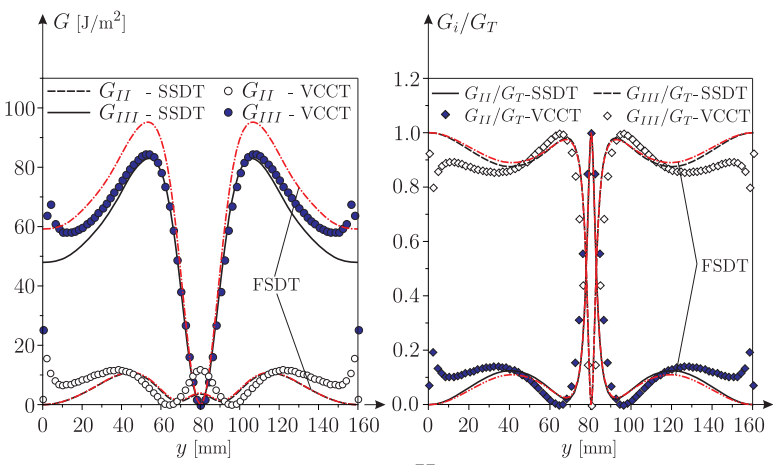

case II

$b=160 \mathrm{~mm}$
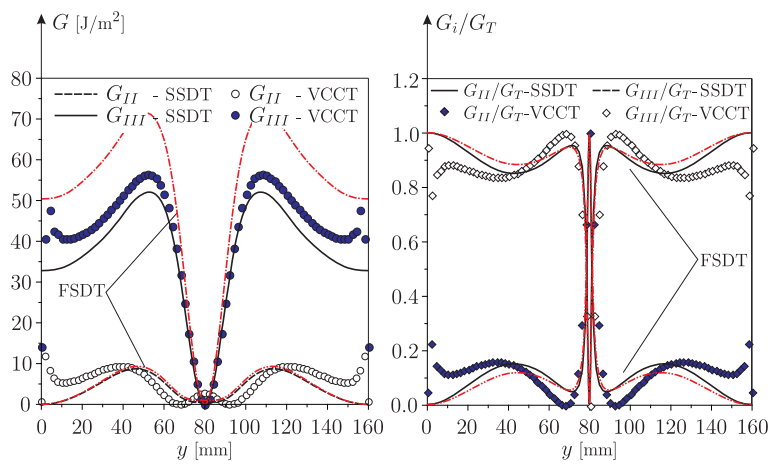

Figure 8. Distribution of the ERRs and mode mixity along the delamination front for cases I and II (refer to Figure 4).

case III

$b=100 \mathrm{~mm}$

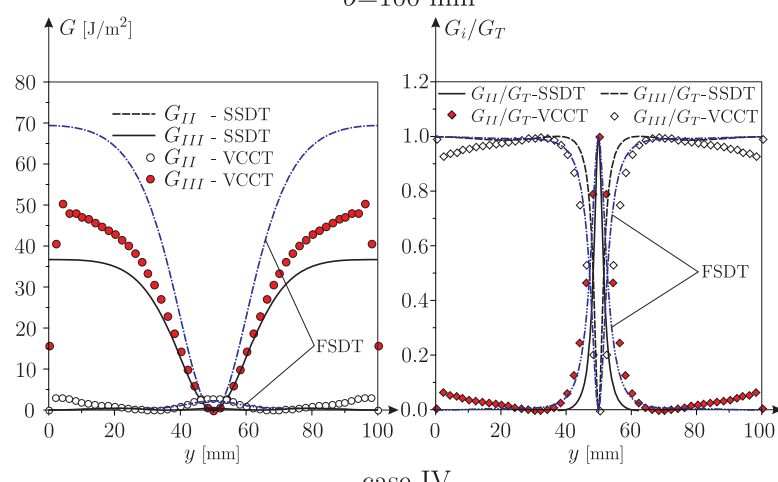

case IV

$b=100 \mathrm{~mm}$
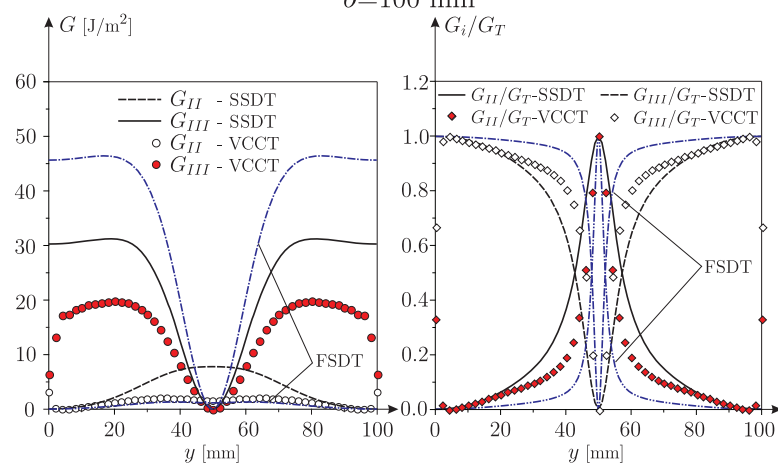

case III

$b=160 \mathrm{~mm}$

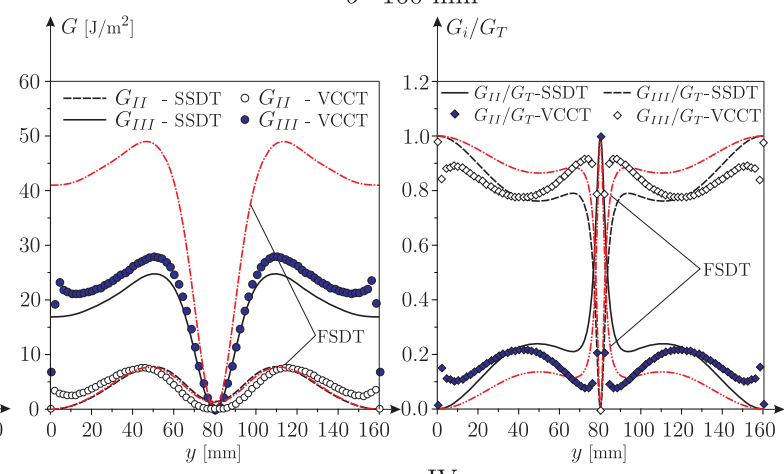

case IV

$b=160 \mathrm{~mm}$
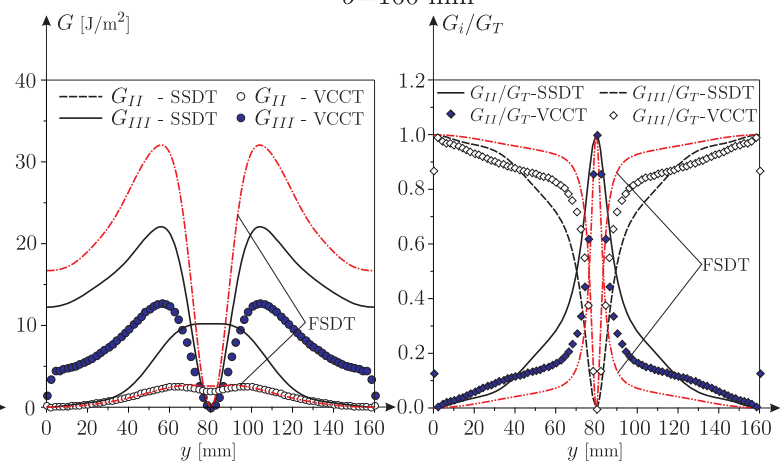

Figure 9. Distribution of the ERRs and mode mixity along the delamination front for cases III and IV (refer to Figure 4). 
cases the SSDT is definitely better than the FSDT especially in the approximation of the shear stress distributions. It is only case IV when the approximation of the shear stresses by the plate solution becomes the worst compared with the FE results. It should be highlighted that based on Figures 4-7 the SSDT estimates significantly more accurately the shear stresses than FSDT, moreover the SSDT is a little bit better again in the prediction of the $\sigma_{x}$ normal stress. Based on the excellent agreement of the analytical and numerical transverse deflections it can be confirmed that it is convenient to choose the midplane to be the reference plane even in the case of asymmetrically delaminated plates. It is also noteworthy that the stress results by FE calculation depend on the crack tip element size. The literature recommends the crack tip elements to be between the one quarter and one half of a single layer thickness for the application of the VCCT [147]. It is obvious that one can use the same mesh for the calculation of the ERRs and stresses. Thus, the dependence of the stresses on the FE size could be reduced.

\subsection{ERR and mode mixity}

Figures 8 and 9 present the ERRs $\left(G_{I I} \equiv J_{I I}, G_{I I} \equiv J_{I I I}\right)$ and mode mixity distributions over the plate width. In each case (I-IV) the analytical results by SSDT (continuous and dashed black line) and FSDT [131] (red and blue dashed dotted and dashed double dotted lines) are plotted by the lines, the VCCT (FE) results are represented by the symbols. The location of the delamination in the through thickness direction is given in the left-hand sides of Figure 4-7 for each cases. The results for cases I and II are presented in Figure 8. For case I, SSDT and FSDT provides the same $G_{I I}$, the SSDT underpredicts $G_{I I I}$ compared to the VCCT results. In contrast, FSDT overpredicts $G_{I I I}$. At the edges $(y=0$ and $y=b)$ the difference between the analytical and FE solution becomes larger. This is attributed to the substantial difference between the SSDT and the 3D FE solution. At the edges the shear stress does not vanish in accordance with SSDT (and neither by FSDT), in contrast in the FE model the edges are traction-free surfaces, except those parts where the kinematic BCs are imposed. Based on the results for $b=160 \mathrm{~mm}$ (case I in Figure 8) it is seen that the nature of the mode-II ERR distribution is somewhat different compared with the FE result: the middle region $(y=70 . .90 \mathrm{~mm})$ is underpredicted, then a little overprediction appears $(y=45 \ldots 70 \mathrm{~mm}$ and $y=90 \ldots 115 \mathrm{~mm})$, while the side regions $(y=0 \ldots 45 \mathrm{~mm}$ and $y=115 \ldots 160 \mathrm{~mm}$ ) are underpredicted again by SSDT. The possible reason for the wrong prediction of the middle region with respect to the mode-II component is that SSDT assumes that the transverse shear strains and stresses are piecewise linear, and therefore they do not satisfy the dynamic (tractionfree) boundary conditions at the free surfaces. Because of the relatively wrong prediction of strains and stresses the $J$-integral is estimated with moderate differences compared to the FE model. It can be seen that the FSDT overpredicts slightly the mode-III ERR by FE solution, while the SSDT provides a better fit to the FE results. The mode mixity $\left(G_{i} / G_{T}\right)$ distributions are also shown in Figure 8 (cases I and II). The analytical and numerical solutions agree well if $b=100 \mathrm{~mm}$, but the at the edges $(y=0$ and $y=b)$ the mismatch is the highest. For case II $(b=160 \mathrm{~mm})$ in Figure 8 (right-hand side) the mode ratio agrees in the middle region $(y=45 \ldots 115 \mathrm{~mm})$, at the edges the difference takes the maximum again. In accordance with Figure 9 it is shown that in case III the FSDT solution is not acceptable to describe the mode-III ERR (and so the mode ratios) for both plate width (diagrams at top in Figure 8), while the SSDT is still reasonable. In case IV (bottom diagrams in Figure 9) the agreement between the SSDT and FE solution becomes the worst, and the analytical model leads to erroneous results. The reason for that is the wrong prediction of the interlaminar shear stresses and the violation of dynamic boundary conditions. The shear forces can be obtained by the integration of the shear stress distributions at a given location. It can be seen, that in cases I and II both the FSDT and SSDT approximates well the area under the curve by FE solution. From the point of view of FSDT case III is the critical case: the FSDT approximates badly the area under the curves of the shear stresses. In contrast, the SSDT is still accurate in this case. Considering case IV in Figure 8, it can be seen, that locally (for the top and bottom plates separately) the SSDT does not approximate well the shear stress distributions (especially for $\tau_{y z}$ ). This leads to the fact that the SSDT gives erroneous result for the ERRs in case IV. Although based on (54)-(55) the ERRs are not influenced directly by the shear forces, through the equilibrium equations they affect significantly the results. The final conclusion is that the SSDT is applicable only for cases I-III (FSDT is reasonable only in cases I and II), or strictly speaking, when the delamination is not too close to the boundary surface of the plate. Moreover, the deviations between the stresses 
from the different theories are related to the inadequacy of the order of the theory used. Also, it is clear, that the presence of the delamination induces complex deformations along the delamination front, which can be captured well by the SSDT, but the satisfaction of the dynamic boundary conditions is very important if the top or bottom plate is relatively thin compared with the global thickness. This indicates that the problem of delaminated composite plates could be better described by higher-order plate theories, e.g. by Reddy's third-order theory [132] but the development of a possible fourth-order plate theory or layerwise theories is also an alternative in this respect.

\section{Conclusions}

The problem of antiplane-inplane shear mode delamination was investigated in this paper using secondorder shear deformable plate theory. A novel double-plate system was developed utilizing the SEKC, which defines the continuity conditions between the top and bottom plate elements (two equivalent single layers) of the uncracked region and the location of the reference plane. The governing equations of the problem were derived and it was shown that there is a significant coupling among the stress resultants of the plate. The problem of a delaminated simply supported plate was solved using Lévy plate formulation and the state-space model. The solution was provided for the displacement, strain and stress fields, besides the mode-II and mode-III $J$-integrals were calculated. The results showed that compared with the FE solutions the slope of the displacement distributions agree very well. It was elaborated that due to the delamination the stress distribution becomes strongly asymmetric and sharp peaks appear at the position of the delamination. The $J$-integral distributions along the delamination front were calculated and compared with FE results based on the virtual crack-closure technique. Four cases were investigated by varying the position of the delamination in the thickness direction and it was found that the SSDT gives reasonable results for the $J$-integral, except for the last case when the delamination was $0.5 \mathrm{~mm}$ close to the boundary surface of the $4.5 \mathrm{~mm}$ thick plate. The reason for the poor agreement of this case was the bad approximation of the interlaminar shear stresses. More clearly the second-order plate theory provides a linear approximation of the shear stresses in the through-thickness coordinate, which becomes insufficient if the delamination is separated by only a thin layer from the free boundary of the plate. Based on the present work an important conclusion is that the accurate approximation of the interlaminar shear stresses is essential to create an advanced plate model even in the case when the plate is relatively thin. Therefore, in the near future the third-and fourth-order plate theories will be utilized to develop a more accurate description of the problem of delaminated orthotropic plates. The SEKC requirements can be utilized to solve vibration problems in cracked beams and plates, as well as the dynamic stability of delaminated composite and sandwich structures.

\section{Funding}

This work was supported by the János Bolyai Research Scholarship of the Hungarian Academy of Sciences and the Hungarian National Scientific Research Fund (OTKA) (grant number 44615-066-15 (108414)).

\section{References}

[1] Rizov, V, Shipsha, A, and Zenkert, D. Indentation study of foam core sandwich composite panels. Compos Struct 2005; 69: 95-102.

[2] Rizov, VI. Non-linear indentation behavior of foam core sandwich composite materials - A 2D approach. Computat Mater Sci 2006; 35: 107-115.

[3] Zammit, AD, Feih, S, and Orifici, AC. 2D numerical investigation of pre-tension on low velocity impact damage of sandwich structures. In 18th international conference on composite materials (ICCM18), 21-26 August, Jeju International Convention Center, Jeju Island, South Korea.

[4] Burlayenko, VN, and Sadowski, T. A numerical study of the dynamic response of sandwich plates initially damaged by low-velocity impact. Computat Mater Sci 2012; 52: 212-216.

[5] Ahn, JS, Woo, KS, and Lee, DW. Delamination analysis of carbon fiber-reinforced peek using coarse mesh. Adv Mater Res 2012; 538-541: 1624-1629.

[6] Ahn, JS, Kim, YW, and Woo, KS. Analysis of circular free edge effect in composite laminates by p-convergent globallocal model. Int J Mech Sci 2013; 66: 149-155. 
[7] Marat-Mendes, RM, and Freitas, MM. Failure criteria for mixed mode delamination in glass fibre epoxy composites. Compos Struct 2010; 92(9): 2292-2298.

[8] Zhou, W, Liang, X, Li, Y, et al. Acoustic emission monitoring for delaminated composites under bending damage failure condition. Appl Mech Mater 2013; 310: 51-54.

[9] Goodmiller, G, and TerMaath, S. Investigation of composite patch performance under low-velocity impact loading. In 55th AIAA/ASME/ASCE/AHS/SC structures, structural dynamics, and materials conference, National Harbor, MD.

[10] Cherepanov, GP. Methods of Fracture Mechanics: Solid Matter Physics. Dordrecht: Kluwer Academic Publishers, 1997.

[11] Adams, DF, Carlsson, LA, and Pipes, RB. Experimental characterization of advanced composite materials, 3rd end. Boca Raton FL: CRC Press, 2000.

[12] Anderson, TL. Fracture Mechanics - Fundamentals and Applications,3rd edn. Boca Raton, FL: CRC Press/Taylor \& Francis Group, 2005.

[13] Gardeazabal, D, He, Z, and Kotousov, A. On influence of non-singular states on brittle fracture. Int J Fracture 2014; 185: 201-208.

[14] Hajikazemi, M, and Sadr, M. A variational model for stress analysis in cracked laminates with arbitrary symmetric layup under general in-plane loading. Int J Solids Struct 2014; 51: 516-529.

[15] Hajikazemi, M, and Sadr, M. Stiffness reduction of cracked general symmetric laminates using a variational approach. Int $J$ Solids Struct 2014; 51: 1483-1493.

[16] Hamed, MA, Nosier, A, and Farrahi, GH. Separation of delamination modes in composite beams with symmetric delaminations. Mater Des 2006; 27: 900-910.

[17] Sorensen, L, Botsis, J, Gmür, T, et al. Delamination detection and characterisation of bridging tractions using long FBG optical sensors. Compos A Appl Sci Manuf 2007; 38(10): 2087-2096.

[18] Islam, MM, and Kapania, RK. Delamination growth using cohesive zone model for adhesive bonding under compression. In Proulx, T (ed.), Experimental and Applied Mechanics, volume 6. New York: Springer, pp. 527-536.

[19] Islam, MM, and Kapania, RK. Global-local finite element analysis of adhesive joints and crack propagation. $J$ Aircraft 2014; 51(1): 310-319.

[20] Kim, S, Kim, JS, and Yoon, H. Experimental and numerical investigations of mode I delamination behaviors of woven fabric composites with carbon, kevlar and their hybrid fibers. Int J Precision Eng Manuf 2011; 12(2): 321-329.

[21] Peng, L, Zhang, J, Zhao, L, et al. Mode I delamination growth of multidirectional composite laminates under fatigue loading. J Compos Mater 2011; 45(10): 1077-1090.

[22] Jumel, J, Budzik, MK, and Shanahan, MER. Beam on elastic foundation with anticlastic curvature: Application to analysis of mode I fracture tests. Eng Fract Mech 2011; 78(18): 3253-3269.

[23] Salem, NB, Budzik, MK, Jumel, J, et al. Investigation of the crack front process zone in the double cantilever beam test with backface strain monitoring technique. Eng Fract Mech 2013; 98: 272-283.

[24] Arrese, A, Carbajal, N, Vargas, G, et al. A new method for determining mode II R-curve by the end-notched flexure test. Eng Fract Mech 2010; 77(1): 51-70.

[25] Argüelles, A, Viña, J, Canteli, AF, et al. Influence of resin type on the delamination behavior of carbon fiber reinforced composites under mode-II loading. Int J Damage Mech 2011; 20(7): 963-977.

[26] Rizov, V, and Mladensky, AS. Analysis of mode II crack in bilayered composite beam. J Theoret Appl Mech 2012; 42(2): $67-78$.

[27] Nikbakht, M, and Choupani, N. Fracture toughness characterization of carbon-epoxy composite using arcan specimen. World Acad Sci Eng Technol 2008; 41: 738-744.

[28] Yoshihara, H, and Satoh, A. Shear and crack tip deformation correction for the double cantilever beam and three-point end-notched flexure specimens for mode I and mode II fracture toughness measurement of wood. Eng Fract Mech 2009; 76(3): 335-346.

[29] Bennati, S, Colleluori, M, Corigliano, D, et al. An enhanced beam-theory model of the asymmetric double cantilever beam (ADCB) test for composite laminates. Compos Sci Technol 2009; 69(11-12): 1735-1745.

[30] Kenane, M, Benmedakhene, S, and Azari, Z. Fracture and fatigue study of unidirectional glass/epoxy laminate under different mode of loading. Fatigue Fract Eng Mater Struct 2010; 33(5): 285-293.

[31] Davidson, B, Bansal, A, Bing, Q, et al. Geometrically nonlinear determination of energy release rate and mode ratio in single leg bending tests. J Reinf Plast Compos 2009; 28(15): 1881-1901.

[32] Jumel, J, Budzik, MK, and Shanahan, MER. Process zone in the single cantilever beam under transverse loading. part I: Theoretical analysis. Theoret Appl Fract Mech 2011; 56(1): 7-12.

[33] da Silva, LFM, Estevez, VHC, and Chavez, FJP. Fracture toughness of a structural adhesive under mixed mode loadings. Materialwissensch Werkstofftech 2011; 42(5): 460-470.

[34] Fernández, MV, Moura, MFSF, da Silva, AT, and Marques, LFM. Mixed-mode fatigue/fracture characterization of composite bonded joints using the single-leg bending test. Compos A Appl Sci Manuf 2013; 44: 63-69.

[35] de Baere, I, Jacques, S, Van Paepegem, W, et al. Study of the mode I and mode II interlaminar behaviour of a carbon fabric reinforced thermoplastic. Polymer Testing 2012; 31: 322-332. 
[36] Bennati, S, Fisicaro, P, and Valvo, PS. An enhanced beam-theory model of the mixed-mode bending (MMB) test - Part I: Literature review and mechanical model. Meccanica 2013; 48: 443-462.

[37] Bennati, S, Fisicaro, P, and Valvo, PS. An enhanced beam-theory model of the mixed-mode bending (MMB) test - Part II: Applications and results. Meccanica 2013; 48(2): 465-484.

[38] Rizov, V, Shindo, Y, Horiguchi, K, et al. Mode III interlaminar fracture behaviour of glass fiber reinforced polymer woven laminates at 293 to 4 k. Appl Compos Mater 2006; 13: 287-304.

[39] Szekrényes, A. Improved analysis of the modified split-cantilever beam for mode III fracture. Int J Mech Sci 2009; 51(9-10): 682-693.

[40] Yoshihara, H. Examination of the 4-ENF test for measuring the mode III R-curve of wood. Eng Fract Mech 2006; 73: 42-63.

[41] Marat-Mendes, RM, and Freitas, MM. Characterisation of the edge crack torsion (ECT) test for the measurement of the mode III interlaminar fracture toughness. Eng Fract Mech 2009; 76: 2799-2809.

[42] Suemasu, H, and Tanikado, Y. Delamination propagation behavior and the fracture toughness of composite laminates under shear fracture mode. In 27th Annual Technical Conference of the American Society for Composites 2012, Held Jointly with 15th Joint US-Japan Conference on Composite Materials and ASTM-D30 Meeting, pp. 367-379.

[43] Szekrényes, A. The influence of crack length and delamination width on the mode-III energy release rate of laminated composites. J Compos Mater 2011; 45(3): 279-294.

[44] Johnston, AL, Davidson, BD, and Simon, KK. Evaluation of new test methods for the determination of $g_{\text {IIIc }}$ of laminated polymeric composites. In 27th Annual Technical Conference of the American Society for Composites 2012, Held Jointly with 15th Joint US-Japan Conference on Composite Materials and ASTM-D30 Meeting, pp. 120-139.

[45] Mehrabadi, FA, and Khosravan, M. Mode III interlaminar fracture in woven glass/epoxy composite laminates. World Acad Sci Eng Technol 2013; 73: 479-483.

[46] Johnston, A, Davidson, B, and Simon, K. Assessment of split-beam-type tests for mode III delamination toughness determination. Int J Fracture 2014; 185(1-2): 31-48.

[47] Johnston, A, and Davidson, B. Intrinsic coupling of near-tip matrix crack formation to mode III delamination advance in laminated polymeric matrix composites. Int J Solids Struct 2014; 51(13): 2360-2369.

[48] Rodríguez-González, JA, May-Pat, A, and Avilés, F. A beam specimen to measure the face/core fracture toughness of sandwich materials under a tearing loading mode. Int J Mech Sci 2014; 79: 84-94.

[49] Szekrényes, A. Interlaminar fracture analysis in the $G_{I}-G_{I I I}$ plane using prestressed transparent composite beams. Compos A Appl Sci Manuf 2009; 40(10): 1621-1631.

[50] Szekrényes, A. Delamination fracture analysis in the $G_{I I} G_{I I I}$ plane using prestressed composite beams. Int $J$ Solids Struct 2007; 44(10): 3359-3378.

[51] Suemasu, H, Kondo, A, Gozu, K, et al. Novel test method for mixed mode II and III interlaminar fracture toughness. Adv Compos Mater 2010; 19(4): 349-361.

[52] Ho, SL, and Tay, AAO. A numerical analysis of penny-shaped delaminations in an encapsulated silicon module. In Proceedings of the electronic components and technology conference, pp. 1115-1121.

[53] Kondo, A, Sato, Y, Suemasu, H, et al. Fracture resistance of carbon/epoxy composite laminates under mixed-mode II and III failure and its dependence on fracture morphology. Adv Compos Mater 2011; 20(5): 405-418.

[54] Kondo, A, Sato, Y, Suemasu, H, et al. Characterization of fracture resistance of carbon/epoxy composite laminates during mixed-mode II and III stable damage propagation. J Jap Soc Compos Mater 2010; 36(5): 179-188.

[55] Nikbakht, M, Choupani, N, and Hosseini, SR. 2D and 3D interlaminar fracture assessment under mixed-mode loading conditions. Mater Sci Eng A 2010; 516(1-2): 162-168.

[56] Szekrényes, A. Interlaminar fracture analysis in the $G_{I \Gamma} G_{I I I}$ plane using prestressed transparent composite beams. Compos A Appl Sci Manuf 2012; 43(1): 95-103.

[57] Miura, M, Shindo, Y, Takeda, T, et al. Interlaminar fracture characterization of woven glass/epoxy composites under mixed-mode II/III loading conditions at cryogenic temperatures. Eng Fract Mech 2012; 96: 615-625.

[58] Mehrabadi, FA. Analysis of pure mode III and mixed mode (III + II) interlaminar crack growth in polymeric woven fabrics. Mater Des 2013; 44: 429-437.

[59] Mladensky, AS, and Rizov, V. Analysis of mixed mode II/III crack in bilayered composite beam. J Theoret Appl Mech 2013; 42(4): 41-52.

[60] Davidson, BD, Sediles, FO, and Humphrey, KD. A shear-torsion-bending test for mixed-mode I-II-III delamination toughness determination. In 25th Technical Conference of the American Society for Composites and 14th US-Japan Conference on Composite Materials, 20-22 September 2010, Dayton, Ohio, USA, volume 2, pp. 1001-1020.

[61] Szekrényes, A. Interlaminar fracture analysis in the $G_{I} G_{I I} G_{I I I}$ space using prestressed transparent composite beams. $J$ Reinf Plast Compos 2011; 30(19): 1655-1669.

[62] Davidson, BD, and Sediles, FO. Mixed-mode I-II-III delamination toughness determination via a shear-torsionbending test. Compos A Appl Sci Manuf 2011; 42(6): 589-603.

[63] Naganarayana, BP, and Atluri, SN. Strength reduction and delamination growth in thin and thick composite plates under compressive loading. Computat Mech 1995; 16(3): 170-189. 
[64] Ousset, Y, and Roudolff, F. Numerical analysis of delamination in multilayered composite plates. Computat Mech 1997; 20: $122-126$.

[65] Borovkov, A, Palmov, V, Banichuk, N, et al. Macro-failure criterion for the theory of laminated composite structures with free edge. Comput Struct 2000; 76(1-3): 195-204.

[66] Krawczuk, M, Ostachowicz, W, and Zak, A. Dynamics of cracked composite material structures. Computat Mech 1997; 20: 79-83.

[67] Chattopadhyay, A, Radu, AG, and Dragomir-Daescu, D. A higher order plate theory for dynamic stability analysis of delaminated composite plates. Computat Mech 2000; 26: 302-308.

[68] Hosseini-Hashemi, S, Fadaee, M, and Taher, HRD. Exact solutions for free flexural vibration of Lévy-type rectangular thick plates via third-order shear deformation. Appl Math Modell 2011; 35(2): 708-727.

[69] Krueger, R, Shivakumar, K, and Raju, IS. Fracture mechanics analyses for interface crack problems A review. In 54th AIAA/ASME/ASCE/AHS/ASC structures, structural dynamics, and materials conference, 8-11 April, Boston, MA, article number AIAA2013-1476.

[70] Ghadiri, M, and Shahani, AR. Mode III fracture analysis of an anisotropic finite wedge with an interfacial crack. Math Mech Solids 2013; 18(8): 823-836.

[71] Liu, G, Tani, J, Watanabe, K, et al. Harmonic wave propagation in anisotropic laminated strips. J Sound Vibr 1990; 139(2): 313-324.

[72] Liu, G, Tani, J, Ohyoshi, T, et al. Transient waves in anisotropic laminated plates, part 1. Theory. J Vibr Acoust Stress Reliab Des 1991; 113(2): 230-234.

[73] Liu, G, Tani, J, Ohyoshi, T, et al. Transient waves in anisotropic laminated plates, part 2. Application. J Vibr Acoust Stress Reliab Des 1991; 113(2): 235-239.

[74] Liu, G, Tani, J, Watanabe, K, et al. Lamb wave propagation in anisotropic laminates. J Appl Mech Trans ASME 1990; 57(4): 923-929.

[75] Han, X, Liu, G, and Lam, K. Transient waves in plates of functionally graded materials. Int J Numer Meth Eng 2001; 52(8): 851-865.

[76] Liu, G, and Achenbach, J. Strip element method for stress analysis of anisotropic linearly elastic solids. J Appl Mech Trans ASME 1994; 61(2): 270-277.

[77] Wang, Y, Lam, K, and Liu, G. Bending analysis of classical symmetric laminated composite plates by the strip element method. Mech Compos Mater Struct 2000; 7(3): 225-247.

[78] Wang, YY, Lam, KY, Liu, GR, et al. A strip element method for bending analysis of orthotropic plates. JSME Int J Ser A Solid Mech Mater Eng 1997; 40(4): 398-406.

[79] Liu, GR, and Achenbach, JD. Strip element method to analyze wave scattering by cracks in anisotropic laminated plates. J Appl Mech Trans ASME 1995; 62(2): 607-613.

[80] Liu, G, Xi, Z, Lam, K, et al. A strip element method for analyzing wave scattering by a crack in an immersed composite laminate. J Appl Mech Trans ASME 1999; 66(4): 898-903.

[81] Xi, Z, Liu, G, Lam, K, et al. A strip element method for analyzing wave scattering by a crack in an axisymmetric crossply laminated composite cylinder. J Appl Mech Trans ASME 2000; 67(2): 427-429.

[82] Xi, Z, Liu, G, Lam, K, et al. A strip-element method for analyzing wave scattering by a crack in an immersed axisymmetric laminated composite cylinder. J Acoust Soc Am 2000; 108(1): 175-183.

[83] Xi, Z, Liu, G, Lam, K, et al. A strip-element method for analyzing wave scattering by a crack in a fluid-filled composite cylindrical shell. Compos Sci Technol 2000; 60(10): 1985-1996.

[84] Liu, GR, Lam, KY, and Tani, J. Strip element method for characterization of flaws in sandwich plates. JSME Int J Ser A Mech Mater Eng 1995; 38(4): 554-562.

[85] Reddy, JN. Mechanics of laminated composite plates and shells - Theory and analysis. Boca Raton, FL: CRC Press, 2004.

[86] Kollár, LP, and Springer, GS. Mechanics of Composite Structures. Cambridge: Cambridge University Press, 2003.

[87] Kumar, Y, and Lal, R. Vibrations of nonhomogeneous orthotropic rectangular plates with bilinear thickness variation resting on Winkler foundation. Meccanica 2012; 47(4): 893-915.

[88] Batista, M. Comparison of Reissner, Mindlin and Reddy plate models with exact three dimensional solution for simply supported isotropic and transverse inextensible rectangular plate. Meccanica 2012; 47: 257-268.

[89] Batista, M. Refined Mindlin-Reissner theory of forced vibrations of shear deformable plates. Eng Struct 2011; 33: 265-272.

[90] Khdeir, AA, and Reddy, JN. Free vibrations of laminated composite plates using second-order shear deformation theory. Comput Struct 1999; 71: 617-626.

[91] Shahrjerdi, A, and Mustapha, F. Second order shear deformation theory (SSDT) for free vibration analyis on a functionally graded quadrangle plate. Recent advances in vibration analysis. Intech, 2011, pp. 60-78.

[92] Izadi, M, and Tahani, M. Analysis of interlaminar stresses in general cross-ply laminates with distributed piezoelectric actuators. Compos Struct 2010; 92: 757-768.

[93] Aragh, BS, Farahani, EB, and Barati, AN. Natural frequency analysis of continuously graded carbon nanotubereinforced cylindrical shells based on third-order shear deformation theory. Math Mech Solids 2013; 18(3): $264-284$. 
[94] Singh, VK, and Panda, SK. Nonlinear free vibration analysis of single/doubly curved composite shallow shell panels. Thin-Walled Structures 2014; 85: 341-349.

[95] Talha, M, and Singh, B. Static response and free vibration analysis of FGM plates using higher order shear deformation theory. Appl Math Modell 2010; 34: 3991-4011.

[96] Panda, SK, and Singh, BN. Nonlinear free vibration of spherical shell panel using higher order shear deformation theory - a finite element approach. Int J Pressure Vessels Piping 2009; 86: 373-383.

[97] Panda, SK, and Singh, BN. Large amplitude free vibration analysis of thermally post-buckled composite doubly curved panel using nonlinear fem. Finite Elements Anal Des 2011; 47: 378-386.

[98] England, AH. Bending solutions for inhomogeneous and laminated elastic plates. J Elasticity 2006; 82(2): $129-173$.

[99] Yang, B, Ding, HJ, and Chen, WQ. Elasticity solutions for functionally graded rectangular plates with two opposite edges simply supported. Appl Math Modell 2012; 36(1): 488-503.

[100] Chang, HH, and Tarn, JQ. Three-dimensional elasticity solutions for rectangular orthotropic plates. J Elasticity 2012; 108(1): 49-66.

[101] Xiang, S, Kang, GW, and Xing, B. A $n$ th-order shear deformation theory for the free vibration analysis on the isotropic plates. Meccanica 2012; 47(8): 1913-1921.

[102] Steigmann, DJ. Refined theory for linearly elastic plates: Laminae and laminates. Math Mech Solids 2012; 17(4): 351-363.

[103] Pruchnicki, E. Two-dimensional model for the combined bending, stretching and transverse shearing of laminated plates derived from three-dimensional elasticity. Math Mech Solids 2011; 16(3): 304-316.

[104] Thai, HT, and Choi, DH. Analytical solutions of refined plate theory for bending, buckling and vibration analyses of thick plates. Appl Math Modell 2013; 37: 8310-8323.

[105] Thai, CH, Tran, LV, Tran, DT, et al. Analysis of laminated composite plates using higher-order shear deformation plate theory and node-based smoothed discrete shear gap method. Appl Math Modell 2012; 36: 5657-5677.

[106] Thai, HT, and Vo, TP. A new sinusoidal shear deformation theory for bending, buckling, and vibration of functionally graded plates. Appl Math Modell 2013; 37: 3269-3281.

[107] Kokkinos, FT, and Reddy, JN. A layerwise boundary integral equation model for layers and layered media. $J$ Elasticity 1995; 38(3): 221-259.

[108] Tahani, M, and Nosier, A. Free edge stress analysis of general cross-ply composite laminates under extension and thermal loading. Compos Struct 2003; 60: 91-103.

[109] Ferreira, AJM, Roque, CMC, Carrera, E, et al. Two higher order zig-zag theories for the accurate analysis of bending, vibration and buckling response of laminated plates by radial basis functions collocation and a unified formulation. $J$ Compos Mater 2011; 45(24): 2523-2536.

[110] Saeedi, N, Sab, K, and Caron, JF. Delaminated multilayered plates under uniaxial extension. Part I: Analytical analysis using a layerwise stress approach. Int J Solids Struct 2012; 49: 3711-3726.

[111] Saeedi, N, Sab, K, and Caron, JF. Delaminated multilayered plates under uniaxial extension. Part II: Efficient layerwise mesh strategy for the prediction of delamination onset. Int J Solids Struct 2012; 49(26): 3727-3740.

[112] Saeedi, N, Sab, K, and Caron, JF. Cylindrical bending of multilayered plates with multi-delamination via a layerwise stress approach. Compos Struct 2013; 95: 728-739.

[113] Saeedi, N, Sab, K, and Caron, JF. Stress analysis of long multilayered plates subjected to invariant loading: Analytical solutions by a layerwise stress model. Compos Struct 2013; 100: 307-322.

[114] Marjanović, M, and Vuksanović, D. Layerwise solution of free vibrations and buckling of laminated composite and sandwich plates with embedded delaminations. Compos Struct 2014; 108: 9-20.

[115] Diaz, AD, Caron, JF, and Ehrlacher, A. Analytical determination of the modes I, II and III energy release rates in a delaminated laminate and validation of a delamination criterion. Compos Struct 2007; 78: 424-432.

[116] Alvarez-Lima, R, Diaz-Diaz, A, Caron, JF, et al. Enhanced layerwise model for laminates with imperfect interfaces - part 1: Equations and theoretical validation. Compos Struct 2012; 94: 1694-1702.

[117] Lerpiniere, A, Caron, JF, Diaz, AD, et al. The $\{\mathrm{LS} 1\}$ model for delamination propagation in multilayered materials at interfaces: A comparison between experimental and finite elements strain energy release rates. Int J Solids Struct 2014; 51(23-24): 3973-3986.

[118] Szekrényes, A. Stress and fracture analysis in delaminated orthotropic composite plates using third-order shear deformation theory. Appl Math Modell 2014; 38: 3897-3916.

[119] Szekrényes, A. Application of Reddy's third-order theory to delaminated orthotropic composite plates. Eur J Mech A Solids 2014; 43: 9-24.

[120] Kotousov, A, Lazzarin, P, Berto, F, et al. Three-dimensional stress states at crack tip induced by shear and anti-plane loading. Eng Fract Mech 2013; 108: 65-74.

[121] Kotousov, A, Berto, F, Lazzarin, P, et al. Three dimensional finite element mixed fracture mode under anti-plane loading of a crack. Theoret Appl Fract Mech 2012; 62: 26-33.

[122] Lee, LJ, and Tu, DW. J integral for delaminated composite laminates. Compos Sci Technol 1993; 47: $185-192$.

[123] Bruno, D, and Greco, F. Mixed-mode delamination in plates: a refined approach. Int J Solids Struct 2001; 38: 9149-9177. 
[124] Davidson, BD, Yu, L, and $\mathrm{Hu}, \mathrm{H}$. Determination of energy release rate and mode mix in three-dimensional layered structures using plate theory. Int J Fracture 2000; 105: 81-104.

[125] Sankar, BV, and Sonik, V. Pointwise energy release rate in delaminated plates. AIAA Journal 1995; $33(7): 1312-1318$.

[126] Szekrényes, A. Interlaminar stresses and energy release rates in delaminated orthotropic composite plates. Int $J$ Solids Struct 2012; 49: 2460-2470.

[127] Szekrényes, A. Interface crack between isotropic Kirchhoff plates. Meccanica 2013; 48(3): 507-526.

[128] Szekrényes, A. Analysis of classical and first-order shear deformable cracked orthotropic plates. J Compos Mater 2014; 48(12): 1441-1457.

[129] Szekrényes, A. Interface fracture in orthotropic composite plates using second-order shear deformation theory. Int $J$ Damage Mech 2013; 22(8): 1161-1185.

[130] Rizov, V, and Mladensky, AS. Elastic-plastic analysis of asymmetric double cantilever beam specimen. Int $J$ Mech Sci 2015; 92: 44-51.

[131] Szekrényes, A. The system of exact kinematic conditions and application to delaminated first-order shear deformable composite plates. Int J Mech Sci 2013; 77: 17-29.

[132] Szekrényes, A. Bending solution of third-order orthotropic Reddy plates with asymmetric interfacial crack. Int $J$ Solids Struct 2014; 51: 2598-2619.

[133] Shahrjerdi, A, Mustapha, F, Bayat, M, et al. Free vibration analysis of solar functionally graded plates with temperaturedependent material properties using second order shear deformation theory. J Mech Sci Technol 2011; 25(9): 1-15.

[134] Shahrjerdi, A, Bayat, M, Mustapha, F, et al. Second-order shear deformation theory to analyze stress distribution for solar functionally graded plates. Mech Based Des Struct Machines 2010; 38: 348-361.

[135] Zhou, ZQ, Fang, X, Cox, B, et al. The evolution of a transverse intra-ply crack coupled to delamination cracks. Int $J$ Fracture 2010; 165(1): 77-92.

[136] Chou, PC, and Pagano, NJ. Elasticity - Tensor, dyadic, and engineering approaches. Princeton, NJ: D. Van Nostrand Company, Inc., 1967.

[137] de Moura, MFSF, Fernandez, MVC, de Morais, AB, et al. Numerical analysis of the edge crack torsion test for mode III interlaminar fracture of composite laminates. Eng Fract Mech 2009; 76(4): 469-478.

[138] Mehrabadi, FA. The use of ECT and 6PBP tests to evaluate fracture behavior of adhesively bonded steel/epoxy joints under mode-III and mixed mode III/II. Appl Adhes Sci 2014; 2(18): 1-15.

[139] Oktem, AS, Alankaya, V, and Soares, CG. Boundary-discontinuous Fourier analysis of simply supported cross-ply plates. Appl Math Modell 2013; 37: 1378-1389.

[140] Thai, HT, and Kim, SE. Lévy-type solution for free vibration analysis of orthotropic plates based on two variable refined plate theory. Appl Math Modell 2012; 36(8): 3870-3882.

[141] Murakami, T, and Sato, T. Three-dimensional $J$-integral calculations of part-through surface crack problems. Comput Struct 1983; 17(5-6): 731-736.

[142] Shivakumar, KN, and Raju, IS. An equivalent domain integral method for three-dimensional mixed-mode fracture problems. Eng Fract Mech 1992; 42(6): 935-959.

[143] Rigby, RH, and Aliabadi, MH. Decomposition of the mixed-mode $J$-integral - revisited. Int J Solids Struct 1998; 35(17): 2073-2099.

[144] Garvan, F. The Maple Book. Boca Raton, FL: Chapman \& Hall/CRC, 2002.

[145] Davidson, BD, Krüger, R, and König, M. Three-dimensional analysis of center-delaminated unidirectional and multidirectional single-leg bending specimens. Compos Sci Technol 1995; 54: 385-394.

[146] Bonhomme, J, Argüelles, A, Castrillo, MA, et al. Computational models for mode I composite fracture failure: the virtual crack closure technique versus the two-step extension method. Meccanica 2010; 45(3): 297-304.

[147] Raju, IJr, Crews, J, and Aminpour, M. Convergence of strain energy release rate components for edge-delaminated composite laminates. Eng Fract Mech 1988; 30(3): 383-396.

\section{Appendix: vectors and matrices for (29)}

The vectors and matrices for (29) are

$$
\begin{aligned}
& \underline{M}_{1}=\left(\begin{array}{lll}
a_{1} & \cdots & a_{15}
\end{array}\right)^{\mathrm{T}}, \\
& \underline{\underline{M}}_{3}=\left(\begin{array}{lll}
c_{1} & \cdots & c_{18} \\
e_{1} & \cdots & e_{18} \\
g_{1} & \cdots & q_{18} \\
j_{1} & \cdots & j_{18}
\end{array}\right), \quad \underline{M}_{2}=\left(\begin{array}{lll}
b_{1} & \cdots & b_{15}
\end{array}\right)^{\mathrm{T}}=\left(\begin{array}{lll}
d_{1} & \cdots & d_{18} \\
f_{1} & \cdots & f_{18} \\
h_{1} & \cdots & h_{18} \\
k_{1} & \cdots & k_{18}
\end{array}\right) \\
& \underline{M}_{5}=\left(\begin{array}{lll}
l_{1} & \cdots & l_{11}
\end{array}\right)^{\mathrm{T}}
\end{aligned}
$$


where the constants denoted by $a-l$ are complicated and therefore these are not presented but can be obtained from the equilibrium equations (23)-(28). The vectors $\underline{U}_{i}, i=1 \ldots 5$ are defined as

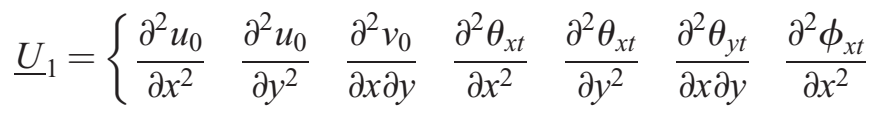

$$
\begin{aligned}
& \left.\frac{\partial^{2} \phi_{x t}}{\partial y^{2}} \quad \frac{\partial^{2} \phi_{y t}}{\partial x \partial y} \quad \frac{\partial^{2} \theta_{x b}}{\partial x^{2}} \quad \frac{\partial^{2} \theta_{x b}}{\partial y^{2}} \quad \frac{\partial^{2} \theta_{y b}}{\partial x \partial y} \quad \frac{\partial^{2} \phi_{x b}}{\partial x^{2}} \quad \frac{\partial^{2} \phi_{x b}}{\partial y^{2}} \quad \frac{\partial^{2} \phi_{y b}}{\partial x \partial y}\right\}^{\mathrm{T}}
\end{aligned}
$$

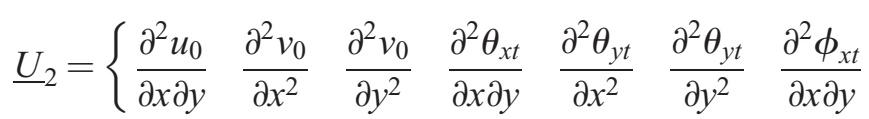

$$
\begin{aligned}
& \left.\frac{\partial^{2} \phi_{y t}}{\partial x^{2}} \quad \frac{\partial^{2} \phi_{y t}}{\partial y^{2}} \quad \frac{\partial^{2} \theta_{x b}}{\partial x \partial y} \quad \frac{\partial^{2} \theta_{y b}}{\partial x^{2}} \quad \frac{\partial^{2} \theta_{y b}}{\partial y^{2}} \quad \frac{\partial^{2} \phi_{x b}}{\partial x \partial y} \quad \frac{\partial^{2} \phi_{y b}}{\partial x^{2}} \quad \frac{\partial^{2} \phi_{y b}}{\partial y^{2}}\right\}^{\mathrm{T}}
\end{aligned}
$$

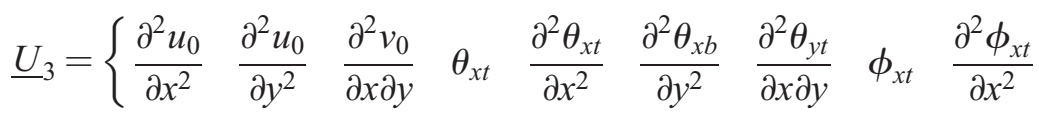

$$
\begin{aligned}
& \left.\frac{\partial^{2} \boldsymbol{\phi}_{x t}}{\partial y^{2}} \quad \frac{\partial^{2} \phi_{y t}}{\partial x \partial y} \quad \frac{\partial^{2} \theta_{x b}}{\partial x^{2}} \quad \frac{\partial^{2} \theta_{x b}}{\partial y^{2}} \quad \frac{\partial^{2} \theta_{y b}}{\partial x \partial y} \quad \frac{\partial^{2} \phi_{x b}}{\partial x^{2}} \quad \frac{\partial^{2} \phi_{x b}}{\partial y^{2}} \quad \frac{\partial^{2} \phi_{y b}}{\partial x \partial y} \quad \frac{\partial w}{\partial x}\right\}^{\mathrm{T}} \\
& \underline{U}_{4}=\left\{\begin{array}{llllllll}
\frac{\partial^{2} u_{0}}{\partial x \partial y} & \frac{\partial^{2} v_{0}}{\partial x^{2}} & \frac{\partial^{2} v_{0}}{\partial y^{2}} & \frac{\partial^{2} \theta_{x t}}{\partial x \partial y} & \theta_{y t} & \frac{\partial^{2} \theta_{y t}}{\partial x^{2}} & \frac{\partial^{2} \theta_{y t}}{\partial y^{2}} & \frac{\partial^{2} \phi_{x t}}{\partial x \partial y}
\end{array} \quad \phi_{y t}\right. \\
& \left.\frac{\partial^{2} \phi_{y t}}{\partial x^{2}} \quad \frac{\partial^{2} \phi_{y t}}{\partial y^{2}} \quad \frac{\partial^{2} \theta_{x b}}{\partial x \partial y} \quad \frac{\partial^{2} \theta_{y b}}{\partial x^{2}} \quad \frac{\partial^{2} \theta_{y b}}{\partial y^{2}} \quad \frac{\partial^{2} \phi_{x b}}{\partial x \partial y} \quad \frac{\partial^{2} \phi_{y b}}{\partial x^{2}} \quad \frac{\partial^{2} \phi_{y b}}{\partial y^{2}} \quad \frac{\partial w}{\partial y}\right\}^{\mathrm{T}}
\end{aligned}
$$

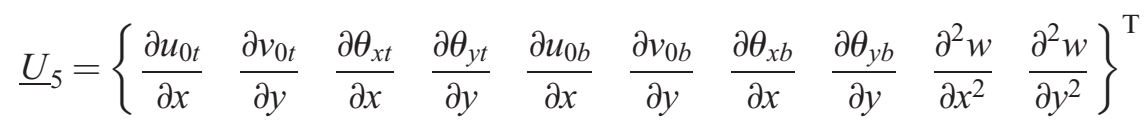

